\title{
METODOLOGÍA Y COMPARACIÓN JURÍDICA EN EL DERECHO PENAL. LA INCIDENCIA DEL DERECHO COMPARADO EN LA ESTRUCTURA DE LA DOGMÁTICA JURÍDICO-PENAL
}

\author{
METHODOLOGY AND LEGAL COMPARISON IN CRIMINAL LAW. \\ THE INFLUENCE OF COMPARATIVE LAW ON THE STRUCTURE \\ OF THE CRIMINAL LAW DOCTRINES
}

JUAN PABLO CASTILLO MORALES*

\section{RESUMEN}

El estudio plantea la tesis de que la cuestión metodológica no ha estado del todo presente en las investigaciones de Derecho penal. Esta desatención se explicaría a partir de la injustificada convicción de que tales aspectos se subentienden en las materias de fondo que ellas abordan. Es lo que ocurre, por ejemplo, cuando sin contextualización previa se recurre al Derecho comparado para desarrollar y justificar una teoría potencialmente aplicable al Derecho (penal) chileno. El artículo busca desarrollar los inconvenientes que la falta de dicha contextualización acarrea y demostrar que en no pocos casos subyace en ella una comprensión defectuosa del Derecho. Con la finalidad de satisfacer dicho objetivo, se ofrecerá una muestra en que lo anterior se apreciaría con mediana claridad. En la parte final, el trabajo condensa la tesis de que la investigación jurídico-penal moderna ha de ser necesariamente interdisciplinaria tanto en la fase de creación legislativa como en la de interpretación propiamente tal.

Palabras claves: Derecho penal; Derecho comparado; Metodología jurídica; Dogmática jurídica; Método científico moderno, Enfoque interdisciplinario.

\footnotetext{
* Doctor en Derecho, Università degli Studi di Trento, Italia. Prof. de Derecho Penal, Universidad Católica del Norte, Antofagasta, Chile. Correo electrónico: juan.castillo@ucn.cl.

Trabajo recibido el 10 de julio de 2019, y aprobado para su publicación el 14 de noviembre de 2019.
} 


\section{ABSTRACT}

This study argues that methodological dimension has not been considered in investigations about Criminal Law. It seems a consequence of believing that methodology is involved in the substantial subjects studied. For instance, it occurs when some theories are constructed from comparative law without a clear methodological justification. Taking this into account, this study attempts to explain the negative effects which arise from the omission of the comparative context, arguing that it could entail a wrong comprehension of Law. Finally, this work supports the thesis about the necessity of developing an interdisciplinary investigation in subjects related to the criminal law. This task involves both the stage of elaborating bills of law and the interpretation of law.

Keywords: Criminal Law; Comparative Law; Legal methodology; legal theory; Modern scientific method; Interdisciplinary approach.

\section{INTRODUCCIÓN}

En un sugerente artículo de 1966, Eduardo Novoa Monreal afirmaba que, sin perjuicio de las ventajas que ofrecía la época para la adopción en Latinoamérica de reglas jurídicas comunes, era igualmente necesario conservar un margen de autonomía. Dicho margen -proseguía Novoaera indispensable para comprender en él "las particularidades (...) de lo exclusivamente nacional", es decir, las costumbres propias de ciertos pueblos y los hábitos y tradiciones que, en siglo y medio de vida independiente, se habían configurado a partir de "las experiencias legislativas del lugar o de sus prácticas judiciales". ${ }^{1}$

Esta prevención antecedía la defensa que el autor hizo del proyecto histórico de integración regional más concreto del que se haya tenido noticia, el Código penal tipo para Latinoamérica; una iniciativa que siempre se cuidó de concebirse a sí misma como un proyecto de legislación modelo y no, en cambio, una especie de Código único, total y cerrado, pues eso

\footnotetext{
${ }^{1}$ Novoa Monreal, Eduardo, "La integración jurídica latinoamericana”, Revista de Derecho Universidad de Concepción, 1966, № 136, p. 57.
} 
habría implicado soslayar, precisamente, "las particularidades geográficas, demográficas, culturales, económicas, etc."” de cada país.

Prescindiendo del específico contexto histórico y del propósito inconfeso que perseguían las palabras de Novoa - defender un proyecto político que él mismo ideó y lideró-, no deja de ser efectivo que en ellas se advierte una excepcional referencia a uno de los argumentos menos tratados por la Dogmática jurídico-penal chilena: la cuestión metodológica (lato sensu) y, en lo específico, la comparación jurídica. ${ }^{3}$

En efecto, uno de los rasgos que se advierte cada vez con mayor intensidad en la investigación jurídica, es la ausencia de preguntas de índole metodológico. Este fenómeno, del que podría sin mayores inconvenientes declararse su transversalidad, adquiere mayor notoriedad tratándose del Derecho penal, parcela en que la explicitación de las decisiones metodológicas ha tendido a la desaparición o, en la mejor de las hipótesis, a una presencia marginal. En ambos casos, ello se debe al injustificado convencimiento de que tales cuestiones están implícitamente contenidas en el análisis del tema de fondo de que se trate, por lo que sería superfluo abordarlas.

La presente contribución busca demostrar lo cierto del diagnóstico antes descrito a partir de la relación -no del todo definida en sus términos-entre Dogmática jurídico-penal y Derecho comparado. Para eso se diferenciará la actitud metodológica de los comparatistas de la que suele caracterizar a una tendencia no despreciable de penalistas. Se enfatizará, asimismo, en la incidencia que en esta materia ha tenido el componente "histórico-político". En seguida, se ofrecerá un ejemplo de las ventajas y desventajas que plantea un instituto de la Parte general como instrumento de comparación jurídica. Finalmente, el artículo propone que la moderna investigación jurídicopenal debe necesariamente ser interdisciplinaria; carácter que ha de detentar tanto en la fase de construcción legislativa como en la de interpretación propiamente tal. Dicho objetivo, sin embargo, exige superar obstáculos no siempre transparentados por los estudios rigurosamente dogmáticos del Derecho penal.

\footnotetext{
${ }^{2}$ Novoa Monreal, cit., (n. 1), pp. 58 y 61.

${ }^{3}$ Tal como ya en la misma época de Novoa lo advertía LaPlazA, Francisco P., "Orígenes y preterición del Derecho penal comparado", en CALABró, A. (Ed.), Estudios jurídicos en Homenaje al Profesor Luis Jiménez de Asúa, Abeledo Perrot, Buenos Aires, 1964, p. 521. A partir de la producción posterior en castellano sobre el tema, el diagnóstico sigue siendo igualmente válido.
} 


\section{UNA CUESTIÓN RELEGADA: LOS ASPECTOS METODOLÓGICOS}

\section{Derecho comparado y acontecimientos históricos de su declive y desarrollo.}

A diferencia de lo que ocurre con otras disciplinas, el Derecho penal suele ser concebido como un banco de pruebas de una serie de materias determinantes para el resto de las ramas del ordenamiento. Se trata, por lo general, de materias que provienen de la Filosofía del Derecho o del Derecho constitucional o privado. Desde teorizaciones del Derecho en general, hasta la cuestión del papel desempeñado (en general) por la judicatura, pasando por la evaluación de una teoría general de interpretación jurídica. Para constatar lo anterior, basta reparar en el hecho de que cada tanto se vuelve a discutir si el Derecho punitivo debe orientarse según las consecuencias o si debe conceder algún valor al precedente judicial.

Sin embargo, otras materias igualmente medulares no han gozado de la misma suerte. Es el caso de la pregunta en torno al valor constitutivo de la comparación para el método dogmático o el debate respecto de la apertura del Derecho penal a otras ciencias sociales. ${ }^{4}$ A diferencia de lo que ocurre en otros países, en Chile no se aprecia una reacción científica ante la extensión del objeto de la ciencia penal a los principios constitucionales, principios internacionales o a la noción misma de los derechos humanos. Eso explica, al menos en parte, que la Dogmática nacional no se haya impuesto la tarea de afinar un método más o menos definido cuando se evoca el dato comparado. ${ }^{5}$ Por eso, ni siquiera cabría reconocer un matiz en el hecho de que la producción bibliográfica más reciente-piénsese en las tesis doctorales y colecciones de prestigiosas editoriales- tenga efectivamente un "enfoque

\footnotetext{
${ }^{4}$ Más optimista en relación a la frecuencia de estas preguntas, en cambio, Donini, Massimo, "La relación entre Derecho penal y política: método democrático y método científico", Revista de estudios de la Justicia, 2004, N 4, p. 50.

${ }^{5}$ Es muy elocuente que la provocación suscitada por MATus AcuÑa, Jean Pierre, "Por qué citamos a los alemanes y otros apuntes metodológicos", Política criminal (U. Talca), 2008, No 5, pp. 1-35, disponible en línea: http://politcrim.com/wp-content/uploads/2019/04/A_5_5.pdf (7 de mayo de 2019), no haya generado más que una aguda réplica; véase, en efecto, van WeEZEL, Alex, “¿Por qué no citamos más (por ejemplo, a los alemanes)? Réplica a J.P. Matus", Política criminal, 2008, No 6, pp. 1-5, disponible en línea: http://politcrim.com/wp-content/uploads/2019/04/Vol3N6D2.pdf (7 de mayo de 2019). Se trata, en todo caso, de una pregunta igualmente abierta en otros contextos, como recientemente ha insistido respecto de los casos español y argentino: Bacigalupo ZAPATER, Enrique, "La recepción de la dogmática penal alemana en España y Latinoamérica”, InDret, 2019, n² 2, pp. 1-21, disponible en línea: http://www.indret.com/pdf/1458.pdf (7 de mayo de 2019), p. 3.
} 
comparativo", ${ }^{6}$ pues dicha producción está lejos de constituir un ejercicio deliberado de autorreflexión en torno a las ventajas metodológicas de la comparación.

Cualquiera sea la causa de esta omisión, sería ciertamente forzado hallarla en una supuesta agudeza dogmática prevenida del peligro ínsito de transformar al Derecho penal en una disciplina autorreferente. No es eso, por cierto, lo que explica que en la región no se haya reparado metodológicamente sobre la pérdida de influjo de la Dogmática italiana, o en las causas del auge que, en su reemplazo, tuvo la alemana. Si se considera, por ejemplo, que el movimiento penal europeo que propició dicho auge no tuvo como prioridad uniformar una dogmática, sino renovar la concepción de la pena y consolidarla en clave preventivo-especial -es decir, materias de carácter empírico mucho más dadas a la comparación- el silencio al respecto es particularmente llamativo. $^{7}$

Por el contrario, si es que algún interés ha suscitado la cuestión metodológica, éste guarda relación con una pregunta cuyo destinatario no es el dogmático, sino el legislador en tanto político. Dicho en otro giro: el foco no apunta a la pregunta sobre cómo conocer mejor un determinado objeto, sino al por qué de la punibilidad de una determinada conducta. Sin perjuicio de que este interrogante -igualmente fundamental- comprende sólo una parte del problema, pues no se hace cargo del sentido y fundamento de institutos que buscan, por ejemplo, eximir o atenuar la responsabilidad penal, no son pocos quienes ven en él la condición necesaria para conceder estatus científico a la Dogmática. Como se puede advertir, el permanente escepticismo de los penalistas respecto de su propia disciplina, visible en la importancia concedida a su carácter fragmentario cual barrera autoimpuesta del trabajo sistemático, se impone con holgura ante la cuestión metodológica. ${ }^{8}$

Si bien la comparación jurídica tiene antecedentes remotísimos en el tiempo, ${ }^{9}$ los peores y mejores momentos de esta disciplina están condicionados

\footnotetext{
${ }^{6}$ Ambos, Kai, "Estado y Futuro del Derecho Penal Comparado", Revista Penal (España), 2018, No 41, pp. 24-25.

${ }^{7}$ Bacigalupo Zapater, cit. (n. 5), p. 9.

${ }^{8}$ Así, recientemente, KINDHÄUSER, Urs, "Acerca del objeto y la tarea de la ciencia del Derecho penal”, Derecho penal contemporáneo. Revista Internacional, 2019, Nº6 (enero-marzo), p. 42.

${ }^{9}$ Véase, al respecto, PRADEL, Jean, "El derecho penal comparado. Breves reflexiones sobre una disciplina del futuro", en Nieto M., A. (coord.), Libro de homenaje al Dr. Marino Barbero Santos: in memoriam, Ed. Universidad Castilla de la Mancha, Salamanca, 2001, pp. 480-483 y, nuevamente, LAPLAZA, cit. (n. 3), pp. 520-529.
} 
por cuestiones de carácter extrajurídico. El Derecho comparado -y, con ello, la preocupación general por lo metodológico- se ha visto históricamente estimulado cuando se desarrolla dentro de una determinada cosmovisión política o si ciertas circunstancias de igual carácter la favorecen. El repaso que sigue confirma el aserto. Las rudimentarias formas de comparación durante todo el periodo que antecedió a la Revolución Francesa se explican, por ejemplo, porque a la sazón el Derecho penal se estructuraba según las necesidades específicas de determinados territorios. El hito de la codificación, por su parte, tampoco contribuyó al desarrollo de la disciplina, conspirando eficazmente contra la universalización que prometió el Iluminismo con la noción de los derechos humanos. Por el contrario, en no pocos casos, los nuevos códigos penales fueron concebidos principalmente como un medio para alcanzar el objetivo político de la unidad nacional. Otro tanto cabría imputar al principio de legalidad. Cuando no es presentado como la conquista política que fue, aparece como un recurso cuyo principal propósito fue contener la avanzada del iusnaturalismo racionalista, que si bien carecía de legitimidad democrática, gozaba de una incontrovertible vocación universalista. En esos términos, el principio se erigió como una vía para simplificar la experiencia jurídica, lo que generó -como era esperablela pérdida de interés hacia todo lo que excedía el marco impuesto por la ley nacional vigente. ${ }^{10}$

Pero si políticas son las causas del retraso, del mismo tenor son las que están detrás de su fortalecimiento y masificación. Más allá de la época histórica de que se trate, un rasgo que siempre ha caracterizado la actividad jurídica es su propensión universalista y dialéctica. No debe perderse de vista, por de pronto, que durante mucho tiempo los juristas compartieron el latín como único idioma de trabajo. La multiplicidad de datos jurídicos, la pluralidad de los sistemas y la heterogeneidad de las fuentes, no siempre fueron vistas como un obstáculo, sino como una ventaja en la búsqueda del escurridizo concepto de justicia. Durante el periodo que medió entre los siglos XIII y XVIII, en un escenario de confusión en materia de fuentes y métodos de interpretación, la cultura jurídica convivió sin mayores inconvenientes con la aspiración universalista del ius commune y del Derecho (penal)

\footnotetext{
${ }^{10}$ Así, Palazzo, Francesco, PAPA, Michele, Lezioni di diritto penale comparato, Giappichelli, Torino, 2013, $3^{\text {a }}$ ed., pp. 8-13. Matiza el impacto (negativo) que la codificación tuvo en el desarrollo de comparación, en cambio, CADOPPI, Alberto, Tra storia e comparazione. Studi di diritto penale comparato, Cedam Padova, 2014, p. 94.
} 
canónico, caracterizados por la ausencia de límites de índole territorial. Desde la vereda opuesta, la secularización también estimuló su desarrollo. El Derecho empezó a ser primordialmente concebido como un instrumento más de la vida social y, en ese orden de ideas, su justificación pasó a medirse en términos de utilidad social. Una vez que comenzaron a primar la eficiencia y los resultados, la comparación devino un método indispensable, pues las soluciones normativas empezaron a ser vistas sólo como datos relativos según los resultados que reportaban. ${ }^{11}$ Precisamente ahí estriba el germen de lo que hoy conocemos como la subsidiariedad del Derecho penal.

\section{Una muestra reciente: el caso italiano.}

El caso italiano es una muestra reciente de cómo este vínculo entre comparación jurídica y política se ha mantenido prácticamente inalterado en el tiempo. Si bien una primera etapa de desarrollo tuvo lugar antes del advenimiento del fascismo ${ }^{12}$-es decir, cuando el clima político era el del liberalismo que antecedió la unificación de Italia y que penetró en las líneas matrices del Código de Zanardelli (1889)- la comparación jurídica sólo irrumpió de manera sostenida en los años ochenta del siglo pasado. Naturalmente, con esto no se pretende afirmar que la comparación y su desarrollo sea cosa del siglo XX. Notables hitos se verificaron a lo largo de todo el siglo XIX gracias a la actividad llevada adelante por juristas de incontrovertible sensibilidad liberal, que veían en la comparación jurídica la forma de poder desarrollar su trabajo y conseguir objetivos políticos

\footnotetext{
${ }^{11}$ Para una descripción detallada del proceso de secularización histórico del Derecho penal, véase, por todos, KindHÄUSER, cit. (n. 8), pp. 26-29, y VinCIGUERRA, Sergio, Le fonti culturali del diritto penale italiano, Cedam, Padova, 2008, pp. 8-15.

${ }^{12}$ Naturalmente, hay excepciones muchas veces desconocidas por lecturas incompletas e interesadas de la obra de ciertos juristas cuyas posiciones políticas estuvieron efectivamente del lado del horror. Un caso paradigmático es el de Arturo Rocco. Una posible causa de su desconocida apertura comparatista es su nulo pronunciamiento respecto del problema de la legitimación del Derecho penal; omisión que -por así decirlo- "contaminó" toda su obra. Se ha perdido de vista, en efecto, que Rocco propuso para su análisis del Derecho un modelo compuesto de elementos antiformalistas, estructurado sobre la aguda distinción entre fuentes del Derecho y fuentes del conocimiento cientifico, categoría en que la comparación (ipero también la Historia, la Criminología y la Sociología criminal!) pueden concurrir sin inconvenientes en función complementaria o subsidiaria. La distancia con la Strafrechtswissenschaft de von Liszt, por ende, no sería tan categórica. Las objeciones de Rocco, más bien, dicen relación con la crítica sin conocimiento del Derecho vigente. Véase, en detalle: Rocco, Arturo, Opere giuridiche. Scritti giuridici vari, Vol. III, Società Editrice del Foro Italiano, Roma, 1933 ("Il problema e il metodo della scienza del diritto penale"), p. 317. En nuestra opinión, incurren en esta forma de leer a Rocco, Palazzo y Papa, cit. (n. 10), p. 19.
} 
concretos. El trabajo desarrollado por Mori, Brusa o Lucchini tuvo, en efecto, un impacto determinante, que bien puede simbolizarse en el hecho de que el propio el Código de 1889 -cuya gestación tomó por lo bajo tres décadas - fuese visto como hijo o fruto de la comparación; otro tanto cabría conjeturar a partir de la circunstancia de que ni siquiera los epígonos del tecnicismo -Rocco y Manzini, por ejemplo- estuvieron en condiciones de eliminar metodológicamente lo que ya entonces tenía estatus de tradición. ${ }^{13}$

La importancia que hoy se le concede, en efecto, tuvo que esperar que el diálogo hermenéutico entre el Código penal de 1930 y la Constitución republicana agotara su rendimiento y que el descrédito ideológico del tecnicismo jurídico fuese lo suficientemente transversal. Por su parte, ni siquiera la propia Constitución de 1948 tenía una particular predilección por el análisis comparado, constatación que no vuelve exagerada la tesis de una integración, antes que una oposición, entre el constitucionalismo penal y la Escuela técnico-jurídica. ${ }^{14}$ Por eso no extraña el motivo que subyace, por ejemplo, en la parquedad de Franco Bricola -pater familia de la interpretación constitucionalmente orientada $-{ }^{15}$ en materia de causas de justificación. Convencido opositor de su extensión analógica, Bricola se manifestó implacablemente en contra del principio del interés preponderante, la acción socialmente adecuada y del medio justo para un fin justo, debido

${ }^{13}$ Donini, cit. (n. 4), p. 46. En detalle, Palazzo y PAPA, cit. (n. 10), pp. 14-17. Sobre el influencia, empleo y utilidad que tuvo la comparación para, precisamente, alcanzar el objetivo de darse por primera vez un código único para toda la península, véase el erudito estudio de CADOPPI, cit. (n. 10), pp. 63-66, 72-73, 87-90 y 100. En el escenario europeo continental, los nombres citados en el texto deben necesariamente ir acompañados de los todavía más fundamentales de Feuerbach y MitTermaier. Sobre el punto, Vorbaum, Thomas, Historia moderna del Derecho penal alemán, Tirant lo Blanch, Valencia, 2018, pp. 77 y $98-99$.

${ }^{14}$ Donini, Massimo, "Tecnicismo giuridico e scienza penale cent'anni dopo. La prolusione di Arturo Rocco (1910) nell'età dell'europeismo giudiziario", Criminalia, 2011, pp. 135 y ss. Recientemente se refiere a la vocación comparatista de la doctrina italiana, LoNDOÑo MARTínEz, Fernando, "Idiosincrasia y dogmática penal italiana. De paso, sobre si acaso Franco Bricola fue un revolucionario o un reformador (Un ejercicio poco 'científico', ma con grande affetto)", 22 de marzo de 2019, disponible en línea: http://www.criminaljusticenetwork.eu/es/post/idiosincrasia-y-dogmatica-penal-italiana-de-paso-sobresi-acaso-franco-bricola-fue-un-revolucionario-o-un-reformador-un-ejercicio-poco-cientifico-ma-congrande-affetto (fecha de consulta: 30 de mayo de 2019).

${ }^{15}$ Sobre el cambio de paradigma metodológico que supuso para adherentes y adversarios la tesis de Franco Bricola, véase, entre otros, Fornasari, Gabriele, "Presentación a 'Relaciones entre Dogmática y Política criminal", Revista de Derecho penal y Criminología (Buenos Aires), 2015, No 10, p. 28. Se trata de un planteamiento metodológico que no tiene, sin embargo, tanto respaldo en política como en el nivel de la academia, prueba de lo cual fue el rechazo de la propuesta introducir positivamente a la Constitución italiana el principio según el cual las normas penales tutelan bienes de relevancia constitucional. Así, DoninI, cit. (n. 4), pp. 39-40. 
al origen alemán de estas teorizaciones. ${ }^{16}$ El vínculo trazado por Bricola entre Dogmática y Política-criminal no se caracterizó nunca por basarse en datos empíricos o en el conocimiento de la efectividad y funciones que el Derecho penal desplegaba en otras latitudes. Se trató, por el contrario, de un planteamiento que identificó en su propia ley (Constitución) algunos fines (principios), y con ellos reintepretó su sistema penal. En razón de lo expuesto, cobra pleno sentido la tesis de que, en el plano de las teorías jurídicas, se advierte una particular lentitud del paso del pensamiento a la acción. ${ }^{17}$

Como ya podrá intuirse, el progreso reciente de la comparación jurídica en Italia, coincide con el proceso de europeización del Derecho penal, el cual aminoró ostensiblemente el nacionalismo técnico-jurídico y que fue clave en la reactivación de un diálogo penal y criminológico que la península había mantenido históricamente con Alemania. ${ }^{18} \mathrm{~A}$ diferencia de lo acaecido en otros países de Europa, en Italia tomaron rápidamente nota de la importancia y utilidad de la comparación ante el innegable cambio de paradigma en materia de fuentes. No se podía menos que afinar un método ante el papel que desde el punto de vista comunitario comenzaban a jugar los tratados internacionales y los tipos penales creados jurisprudencialmente. ${ }^{19}$

Por otro lado, este cambio coincidió con el hecho de que a partir de 1980 una camada considerable de penalistas italianos inició estudios doctorales fuera del país, lo que implicó que toda una generación tomara contacto con culturas, experiencias, métodos y sensibilidades diferentes. En materia de propuestas de lege ferenda, por ejemplo, el reconocimiento

\footnotetext{
${ }^{16}$ Calificándolas incluso de ‘anómalas' o ‘extrajurídicas'. Véase Bricola, Franco, “Teoria generale del reato", en: Canestrari, S., Melchionda, A. (Eds.), Scritti di Diritto penale, Vol. I, T. I, Giuffrè, Milano, 1997, pp. 732-733. Del mismo autor, véase lo que anotamos en Bricola, Franco, "Relaciones entre Dogmática y Política criminal", Revista de Derecho penal y Criminología (Buenos Aires), 2015, No 10, p. 47, nota 87. Cabe advertir, sin embargo, que con posterioridad Bricola parece aceptar la división popularizada por Mezger entre justificantes basadas en el principio del interés preponderante y las que se fundan en la ausencia de interés. Así, por ejemplo, en "Legalità e crisi", en BRICOLA, cit. (n. 14), pp. 1329-1330. Mucho más abierto en este sentido, Rocco, cit. (n. 12), p. 302. Véase, precisamente a propósito de Rocco, Amisano, Maristella, Le esimenti non codificate. Profili di liceità materiale, Giappichelli, Torino, 2003, p. 99, nota 41.

${ }^{17}$ Así, CAdoppr, cit. (n. 10), p. 85; Donini, cit. (n. 4), pp. 40-41.

${ }^{18}$ Lo que ha constituido un "terreno fecundo para las fuerzas más jóvenes del penalismo italiano", al decir de Mantovani, Ferrando, Diritto penale. Parte generale, Cedam, Padova, 2016, $9^{\mathrm{a}}$ ed., p. 38. En un sentido análogo, Donini, "La situazione spirituale della ricerca giuridica scientifica", Cassazione Penale, 2016, Vol. 56, No 5, pp. 1854 y 1863-1864.

${ }^{19}$ En detalle, Viganò, Francesco, "L'influenza delle norme sovranazionali nel giudizio di 'antigiuridicità' del fatto típico", Rivista Italiana de Diritto e Procedura Penale., 2009, p. 1062-1088. Idéntico, CADOPPI, cit. (n. 10), p. 80.
} 
explícito de las exculpantes en el llamado "Progetto Pagliaro" (un proyecto de reforma total del Código) grafica claramente las consecuencias de ese intercambio. Pero no sólo. Se trató también de un intercambio con notables repercusiones en la jurisprudencia constitucional, al punto que no se incurre en una exageración al afirmar que el saber empírico más frecuentemente utilizado por la Corte costituzionale es la evocación general a las experiencias legislativas extrajeras; con ella se mide la conformidad de las incriminaciones a los valores o a los objetivos del legislador. ${ }^{20}$ La derogación formal del delito de oltraggio a pubblico ufficiale (antiguo artículo 341 C.P.) o el reconocimiento jurisprudencial del error de Derecho -por citar sólo un par de ejemplos- son muestras tangibles de la capacidad que tiene la comparación para racionalizar escenarios muchas veces sobrecargados de intensos componentes valorativos o discrecionales. ${ }^{21}$

Una vez que se decide recurrir al instrumento comparado, el paso indispensable del dogmático consistirá, en consecuencia, en la relativización de los puntos de vistas autárquicos. Sólo así se evita sobrevalorar la dogmática propia y su mundo conceptual; actitud muy propia de lo que provocadoramente ha sido denominado "provincialismo nacionalista", no por nada ideológicamente emparentada con escuelas metodológicas que, al prohijar un ideario restringido del Derecho, soslayan la incontrovertible extensión de su objeto. En cambio, al partir de una actitud más modesta respecto de las posibilidades que ofrece el propio Derecho, se asume, en fin, que el objetivo del Derecho penal no es alcanzar la solución perfecta, sino la más democrática y científica ante problemas que surgen en contextos con particularidades e identidades irrepetibles. ${ }^{22}$

\footnotetext{
${ }^{20}$ Similar, Palazzo y PaPA, cit. (n. 10), pp. 29 y 51; Donini, cit. (n. 4), p. 39.

${ }^{21}$ Un par de ejemplos: la sentencia 341/1994 de la Corte Costituzionale, que auguró la ulterior derogación formal del delito del antiguo artículo 341 c.p., dispuso que el prestigio de la administración pública, tutelada mediante la norma que preveía el desacato a la autoridad, era excesiva a la luz de cuanto preveían otros ordenamientos europeos en materias análogas. Explícito en ese sentido el §. 3 de la sentencia. Corte Costituzionale (Italia), 25 de julio de 1994, Rol 341/1994, disponible en línea: http://www.giurcost.org/decisioni/1994/0341s-94.html (vista al 31 de mayo de 2019); lo propio hizo recientemente con la sentencia 141/2019 en que declaró la constitucionalidad de los preceptos que sancionan penalmente el reclutamiento y favorecimiento de la prostitución libremente ejercida (Corte Costituzionale (Italia), 6 de marzo de 2019, Rol 141/2019, disponible en línea: http://www.giurcost. org/decisioni/2019/0141s-19.html); FornASARI, Gabriele, "Conquiste e sfide della comparazione penalistica", en: Dolcini, E.; Paliero, C.E. (eds.), Studi in onore di Giorgio Marinucci. I. Teoria del diritto penale, criminología e Política-criminale, Giuffrè, Milano, 2006, p. 268; CADOPPI, cit. (n. 10), p. 82.

${ }^{22}$ Ambos, cit. (n. 6), pp. 13 y 24; Donini, cit. (n. 4), p. 29 y 45. Atribuyeron el carácter de antídoto contra
} 
La conclusión a la que se puede arribar con este somero repaso del caso italiano es que metodología, comparación y política están indisolublemente asociadas. Lo que ha ocurrido sistemáticamente desde los años noventa del siglo pasado ratifica las razones que hemos esgrimido como estimulantes de la comparación: el clima cultural de los años setenta y ochenta -es decir, el tránsito de la imagen del jurista de mero técnico a (además) crítico del Derecho-, la europeización y los intentos de reforma total del Código, han confluido claramente a la consolidación de la comparación como componente ineludible de la Dogmática.

En síntesis, no es posible alcanzar un completo diagnóstico del Derecho extranjero bajo el manto de una concepción autoritaria o autosuficiente del propio Derecho. La premisa que subyace en una cultura jurídica que admite como instrumento de trabajo el dato comparado, es que, si bien las soluciones tendencialmente uniformes en países similares no pueden ser tenidas verdaderas per se, ciertamente están menos condicionadas por factores político-criminales de carácter local.

\section{DERECHO COMPARADO Y DOGMÁTICA JURÍDICO-PENAL}

\section{La actitud de los comparatistas y el conservadurismo de los penalistas.}

En la búsqueda de causas que expliquen la actual desatención chilena por estas materias, se incurriría en un error histórico atribuirla al hecho de que el positivismo criminológico -movimiento que puso la cuestión del método en primerísimo plano- constituya hoy una corriente de pensamiento obsoleta, ya que si bien este tópico ingresó con propiedad al catálogo de materias propias de la Filosofía jurídica, lo hizo desde un inicio subordinado a la cuestión de la esencia y naturaleza del Derecho; nunca se planteó como un problema aparte y de primer orden. Por lo demás, el carácter abiertamente antimetafísico y antifilosófico del positivismo ${ }^{23}$ no se

el conservadurismo o contra una especie de chauvinismo jurídico, entre otros, RodRíGUEz DevESA, José María, "El Derecho comparado como método de la política criminal", Anuario de ciencias penales, 1966, XIX, Fascículo I, p. 11; y a principios del siglo XX, Zitelmann, Ernst, "Compiti e importanza del diritto comparato" (1900), trad. de Rocco Favale, Rassegna di diritto civile, 1997, N 3, pp. 716-719. ${ }^{23}$ In extenso: De Rivacoba y Rivacoba, Manuel, Elementos de Criminología, Edeval, Valparaíso, 1982, pp. 258 y ss. 
manifestó tan radicalmente en nuestro país. No hay que perder de vista, por de pronto, que Raimundo del Río, el positivista local más insigne del siglo $\mathrm{XX}$, haya sido uno de los pocos en reparar que la investigación y enseñanza del Derecho debía estudiar no sólo su formación originaria y presente, sino también las causas sociales de su nacimiento y la ley de su progreso, para lo cual era indispensable recurrir a la observación e inducción de los hechos históricos y, en particular, a la comparación para determinar el carácter local o universal de ciertas instituciones. ${ }^{24}$

Un factor que innegablemente ha contribuido a lo anterior es la no pertenencia de la cuestión metodológica al Derecho positivo. Eso explica, por lo demás, que la omisión se extienda a otras materias igualmente cardinales, como la delimitación, naturaleza, relación con otras ramas del Derecho, progresión histórica y fundamentación filosófica del Derecho penal. ${ }^{25}$ Esta despreocupación ha repercutido en el empobrecimiento del apartado que, en las obras generales de nuestra disciplina, recibe el nombre de "Introducción". En lo que se refiere específicamente a la comparación jurídica, un desarrollo respecto de su sentido y propósito escasea casi por completo en los manuales chilenos. Esto ocurre tanto en aquellos que efectivamente contienen una Introducción -que es a donde pertenece genuinamente la cuestión del método-, como en los que tratan con mediana detención el concepto y los cometidos de la Dogmática jurídico-penal. Algo similar ocurre en aquellas obras que, ya en la teoría de la ley penal, se ocupan del problema de la interpretación de la ley punitiva, tópico igualmente pertinente para explicitar las ventajas del recurso comparado. ${ }^{26}$ Una situación parcialmente análoga es

\footnotetext{
${ }^{24}$ Como registró hace algunos años MAtus AcuÑa, Jean Pierre, "El positivismo en el derecho penal chileno. Análisis sincrónico y diacrónico de una doctrina de principios del siglo XX que se mantiene vigente", Revista de Derecho (Valdivia), 2007, Vol. XX, No 1, p. 184.

${ }^{25}$ Vacíos sólo parcialmente colmados cuando en el estudio de la Parte especial se alude al bien jurídico tutelado por el tipo penal de que se trate, pues en no pocos casos se insiste en prescindir que cada uno de éstos sólo puede delinearse correctamente si se considera el proceso cultural, con su carga de pasado, su realidad actual y proyección futura. Destacan el estrecho vínculo de la Parte especial con consideraciones de índole cultural, entre otros, DE Rivacoba y Rivacoba, Manuel, "¿Hacia un nuevo conceptualismo jurídico?", Boletín de la Facultad de Derecho, 1998, № 13, p. 111; BACIGALUPO ZAPATER, cit. (n. 5), p. 12, para quien existiría por parte de la Dogmática jurídico-penal alemana una tendencia a no transparentar siempre sus vínculos con la Filosofía, y que se habría manifestado con particular evidencia en España, cuya doctrina sistemáticamente desconoció, por ejemplo, que la teoría final de la acción de Welzel era una cuestión cuyo meollo trascendía "la interpretación del texto legal", es decir, que incidía en sus "fundamentos prejurídicos" (p. 15). Idénticos, aunque respecto del caso italiano, PALAzZO y PAPA, cit. (n. 10), p. 20.

${ }^{26}$ Una excepción, aunque meramente referencial, se encuentra en CURY URzúA, Enrique, Derecho penal. Parte general, Ediciones Universidad Católica de Chile, Santiago, 2009, 9ª ed., p. 148.
} 
posible reconocer en los manuales italianos, ${ }^{27}$ cuya doctrina, sin embargo, ha colocado el problema de la comparación en primer plano desde hace al menos cuarenta años. ${ }^{28}$ Numerosas monografías ejemplifican no sólo una convivencia apacible y enriquecedora entre comparación, Dogmática, Criminología y Ciencia de la legislación, sino, sobre todo, una admirable voluntad de revisar (ahora desde una perspectiva comparada) convicciones científicas defendidas en el pasado. ${ }^{29}$

Lo que debe notarse, sin embargo, es que una explicación de este tenor no puede generar autocomplacencia. Ello develaría que el penalista está más cerca de devenir un exégeta que un cultor del Derecho. Por lo demás, se trataría de una explicación bastante forzada si se repara en que el conjunto de condiciones que permitieron el desarrollo y actual fisonomía de la comparación está hace bastante tiempo sedimentado como para continuar identificando en este factor la causa de su escaso tratamiento. La codificación decimonónica, el desarrollo teórico del positivismo, la crisis del formalismo jurídico (y, con él, el de una cierta idea de legalidad), los excesos de la especulación puramente dogmática, entre otros acontecimientos, son tópicos tan integrados en la cultura jurídica contemporánea que la omisión de estas materias sólo puede ser vista como un incomprensible y preocupante salto lógico. ${ }^{30}$

Antes bien, el retraso de la comparación jurídica en el campo penal se puede explicar por la combinación de dos factores no siempre transparentados por la doctrina: la mutabilidad del objeto de estudio y un cierto conservadurismo gremial. En Derecho penal, en efecto, no sólo cambia el conocimiento que pueda tenerse sobre su objeto de estudio o la perspectiva desde la que es contemplado. Es el objeto mismo el que muta, porque más o menos imperceptiblemente cambian los sistemas políticos y sociales que producen el objeto del saber jurídico, el Derecho. ${ }^{31}$ Ya que ninguna otra rama del ordenamiento jurídico tiene tanto que ver con la

${ }^{27}$ A excepción, por ejemplo, de Mantovani, cit. (n. 18), pp. 31-38, y Pulitanò, Domenico, Diritto penale, Giappichelli, Torino, 2015, $6^{\text {a }}$ ed., pp. 9-13.

${ }^{28}$ Palazzo y Papa, cit. (n. 10), p. 2; Donini, cit. (n. 4), p. 45.

${ }^{29}$ Véanse los ejemplos ofrecidos con exhaustividad por DoninI, cit. (n. 14), p. 147, notas 82 y 83.

${ }^{30}$ PAlazzo y PAPA, cit. (n. 10), p. 2. Para un examen detallado de buena parte de los fenómenos enunciados, véase, por todos, FARALLI, Carla, La filosofia del diritto contemporanea, Laterza, Roma, 2002, pp. 3-10 y 33-45.

${ }^{31}$ Así, entre otros, HruschKa, Joachim, “¿Puede y debería ser sistemática la dogmática jurídico-penal?”, en SÁnchez-Ostiz, P. (dir.), Imputación y Derecho penal. Estudios sobre la teoría de la imputación, Thomson-Aranzadi, Navarra, 2005, p. 254. 
irracionalidad como el Derecho penal, la tormentosa relación del penalista con la política puede ser vista como un esfuerzo permanente de los primeros de racionalizar la necesidad de defensa y venganza. Adicionalmente, se han configurado factores históricos y filosóficos que han contribuido a incrementar esa tensión y, de paso, a extraviar el interés por la metodología y la comparación. No otro que ese fue el efecto de la pretendida necesidad de diferenciar la Dogmática de la Política-criminal o de la creencia según la cual el Derecho penal dispondría de un método propio (algo así como un know how cualificante e irrenunciable); lo propio generaron las tesis del carácter supuestamente neutro del saber científico o la que afirmaba que, en materia de principios, la regla de la mayoría no tiene incidencia. ${ }^{32} \mathrm{Si}$ bien es posible afirmar que, comparativamente, los penalistas padecen en menor medida de un cierto conservadurismo, éste igualmente termina limitando sus capacidades y acciones a una cierta forma de comprender el Derecho, al punto de inhibirlos, salvo en lo que atañe a las cuestiones más contingentes, de la formulación de toda crítica o propuesta de reforma. ${ }^{33}$

En el caso chileno, por ejemplo, es precisamente dicha actitud combinada, naturalmente, con el espíritu conservador de la clase política, la mentalidad insular y una suerte de orgullo gremial por cuerpos normativos que son considerados monumentos de la civilización-, la que ha dificultado una reforma total del Código penal. ${ }^{34} \mathrm{Si}$ se extrapola al caso chileno el tránsito hacia la comparación experimentado en Italia, se puede conjeturar que una posible clave para una deliberada y autoconsciente apertura metodológica venga dada por una reforma ya no del Código punitivo, sino del político, es decir, de su Constitución, ${ }^{35}$ cuya gramática -al plantearse en términos de "principios"- debería tender a ser más universal y, por ende, con una mayor

\footnotetext{
${ }^{32}$ Así, por ejemplo, Donini, cit., (n. 4), pp. 26-27. Recientemente crítico de la tesis según la cual los parámetros de legitimación de las decisiones concernientes a la definición, control y represión de ciertos comportamientos, estarían exentos del juego de las mayorías políticas y acuerdos ideológicos, MaÑalich RafFo, Juan Pablo, "El principialismo político-criminal como fetiche", Revista de Estudios de la Justicia, 2018, № 29, pp. 61-62.

${ }^{33}$ Sobre el conservadurismo de los juristas chilenos, véase la finísima explicación histórica de SQuelLA Narducci, Agustín, Filosofía del Derecho, Editorial Jurídica de Chile, Santiago, 2008, pp. 550 y 560.

${ }^{34}$ Así, recientemente, GuZmán Dalbora, José Luis, "Il codice penale cileno nel prima del tempo", en: Fornasari, G., Corn, E. (eds.) Codice penale della Repubblica del Cile, Cedam, Padova, 2013, p. XXIX.

${ }^{35}$ No deja de ser sintomático del conservadurismo al que hacemos mención que sean dos penalistas italianos quienes de manera directa planteen la necesidad de una reforma constitucional para Chile. Véase, ForNASARI, Gabriele, Corn, Emanuele, "Premessa: così lontano ma così vicino: il vecchio codice penale cileno e il diritto penale in Italia oggi", en: Fornasari, G., Corn, E., cit. (n. 34), pp. IX-XIII.
} 
vocación a la comparación. Por esa vía, además, sería posible enriquecer una Dogmática que en la reflexión más fina ha mostrado tradicionalmente un desapego respecto del texto constitucional. ${ }^{36}$ Un cambio en esta línea, por lo tanto, ampliaría el horizonte de la ciencia penal, volviéndose, desde el punto de vista de su funcionamiento, mucho más exigente, toda vez que no será suficiente tener un conocimiento acabado de las normas. Por el contrario, la experiencia del Derecho penal pasará necesariamente a medirse con conocimientos cuya verificación y control está a cargo -por así decirlo-del mundo laico, lo que, por lo demás, es perfectamente coherente con la circunstancia de que esta disciplina no es sólo un instrumento de pura reafirmación de valores, sino un programa que mira a la propia realidad social y humana que regula. ${ }^{37}$ Como con razón se ha sostenido, si bien el principio no es del todo satisfactorio desde la perspectiva de la precisión, sí lo es, dada su generalidad y capacidad expansiva, desde el prisma de su fuerza reguladora. ${ }^{38}$ En la medida que el principio va más allá de la literalidad de la regula iuris, aquél se sitúa en un grado de abstracción y generalidad en que el aporte cognoscitivo proveniente de la experiencia jurídica extranjera no sólo se ve favorecido, sino que es incluso necesario. ${ }^{39}$ Lo anterior se aprecia claramente en el importante papel desempeñado por los principios generales del Derecho en el desarrollo de las fuentes del Derecho internacional, determinantes, a su vez, en el fortalecimiento de la comparación jurídica. ${ }^{40}$

La actitud del comparatista, en cambio, se halla en los antípodas. Para dar cuenta de lo anterior, basta revisar sus materiales de enseñanza, en los cuales se advierte la formulación continua de preguntas referidas al objeto y

\footnotetext{
${ }^{36}$ Así, SQuella Narducci, cit. (n. 33), p. 564. No es descartable como hipótesis que la falta de diálogo con el texto constitucional se deba a su opinable legitimidad de origen, sobre la que no podemos pronunciarnos en esta sede. Sobre el particular, véase GuzMÁn DALBORA, José Luis, "Relaciones del Derecho penal con el Derecho constitucional, y su concreción en la Constitución política chilena (1980)", Anuario de Filosofia Jurídica y Social, 1994, № 12, pp. 177-179. En cualquier caso, cuando dicho diálogo se configura, el resultado suele ser nefasto, como ocurre, por ejemplo, en materia de minorías étnicas. En detalle, GuZmán DaLbora, José Luis, Cultura y delito, Edeval, Valparaíso, 2018, pp. 185-188 ("Derecho penal y minorías étnicas: planteamiento y liquidación criminalista de un problema político").

${ }^{37}$ Así, Mañalich Raffo, cit. (n. 32), pp. 61-64 y 66-69; en sentido similar, Donini, cit. (n. 4), p. 29.

${ }^{38}$ Así, entre otros, PaLAzzo y PAPA, cit. (n. 10), p. 51.

${ }^{39}$ AnCEL, Marc "Reflexiones sobre estudios de Derecho comparado", en: JimÉNEZ, M. (ed.), Problemas actuales de las Ciencias penales y la Filosofía del Derecho, Homenaje a Luis Jiménez de Asúa, Pannedille, Buenos Aires, 1970, pp. 614-615; PAlazzo y PAPA, cit. (n. 10), p. 23.

${ }^{40}$ Así, Fornasari, cit. (n. 21), pp. 273-275; véase, asimismo, AmBos, cit. (n. 6), pp. 10-11.
} 
finalidades de la comparación. ${ }^{41}$ La perspectiva de trabajo del comparatista es el denominado "punto de vista externo", caracterizado por focalizar la atención en las fuentes que tradicionalmente han sido minusvaloradas (la doctrina, la jurisprudencia) por ciertas lecturas ortodoxas de la separación de poderes, que han reducido el momento valorativo del Derecho a la actividad desplegada por el legislativo. Son los propios comparatistas, por el contrario, quienes se apresuran en advertir que una correcta comparación no puede reducirse a una simple lectura codicis. Cuando la comparación tiene, por el contrario, una finalidad puramente cognoscitiva o de información, suele carecer del carácter interdisciplinario que la distingue y, precisamente por eso, es inidónea para profundizar en los complejos problemas del sistema penal. ${ }^{42}$ De manera muy aislada se ha explicitado entre los penalistas que el examen de la legislación extranjera es sólo el paso previo para una genuina comparación jurídica, cuya complejidad la convierte siempre en una indagación "sociológica-jurídica". ${ }^{43}$ Todavía más: la tendencia que se advierte entre los penalistas es de una inexplicable e injustificada elusión del material normativo - que es, ante todo, cultural- sobre el que Dogmática extranjera teoriza o interpreta determinados problemas.

El material de trabajo del comparatista consiste en todas las reglas capaces de dirigir el comportamiento de las relaciones interindividuales: desde las que se gestan en el ámbito de un grupo profesional, hasta las que maduran en el seno de una comunidad donde se comparten orientaciones políticas o religiosas. ${ }^{44}$ Desde el momento que orientan el comportamiento, el comparatista concede a las normas sociales la atribución de presidir la distribución imperativa de los valores y bienes que satisfacen los intereses y necesidades al interior de un grupo. ${ }^{45} \mathrm{~A}$ esto aluden algunos especialistas cuando se refieren a las "reglas operacionales" que efectivamente regulan

\footnotetext{
${ }^{41}$ Somma, Alessandro, "A chi servono i comparatisti? Diritto comparato, postdiritto e ruolo della comparazione", Comparazione e Diritto Civile, 2017, n 2, 7 p., disponible en línea: http://www. comparazionedirittocivile.it/download/volumi/201702.pdf (visitada al 13 de marzo de 2019).

${ }^{42}$ Palazzo y PAPA, cit. (n. 10), pp. 36-37 y 47.

${ }^{43}$ Así, por ejemplo, JimÉnez de AsúA, Luis, Tratado de Derecho penal. Tomo I, Losada, Buenos Aires, 1977, 4a ed., actualizada, p. 685; FernÁndez Albor, Agustín, “Aportación al estudio comparado de los sistemas penales europeos", Anuario de Ciencias penales, 1966, T. XIX, Fascículo I, pp. 40-41; López Rey Arrojo, Manuel, "Criterios y perspectivas de la codificación penal", Revista de Derecho penal y Criminología (Buenos Aires), 2012, № 11, p. 239.

${ }^{44}$ Así, indirectamente, SQuella Narducci, cit. (n. 33), p. 532.

${ }^{45}$ Somma, Alessandro, Introducción al Derecho comparado, Trad. de Esteban Conde Naranjo, Ed. Universidad Carlos III de Madrid, Madrid, 2015, pp. 28-30.
} 
los fenómenos de la experiencia jurídica, diferentes de la "verbalización” de dichas reglas (códigos, leyes y sentencias). Así como ocurre con la naturaleza y los hechos históricos, en la experiencia jurídica el contenido de las reglas que verdaderamente regulan la sucesión de los fenómenos también es tácito y desconocido. La regla operacional, a diferencia de la proclamación contenida en la verbalización de una regla, se descubre de manera progresiva, esto es, en la medida que se van reconociendo los factores capaces de delinear dicha regla operacional. ${ }^{46}$ Acá el contraste con el Derecho penal es todavía más evidente, pues esta perspectiva exige examinar el Derecho jurisprudencial, es decir, el que se forma dentro, fuera y junto al principio de legalidad. ${ }^{47}$ La excesiva asociación del Derecho a la norma jurídica, por el contrario, ha conducido a una infravaloración de la jurisprudencia como fuente del Derecho y, sobre todo, ha prescindir del papel institucional que, dentro de los límites legales y constitucionales, desarrolla. ${ }^{48}$ De ahí la afinidad de la comparación con las llamadas teorías institucionalistas, consideradas un inevitable punto de referencia para el comparatista; la comparación sólo producirá resultados útiles cuando, además de evaluar la similitud o divergencia normativa y cultural, mida las consecuencias de las normas en su concreta aplicación. Por eso contempla en su estudio contextos espaciotemporales particularmente acotados.$^{49}$ Desde esta perspectiva, una correcta comparación jurídica deberá atender al tipo de organización de la justicia penal, la mentalidad de los operadores, el tipo de formación que reciben los juristas y la retórica de la argumentación normalmente empleada. ${ }^{50}$

\footnotetext{
${ }^{46}$ Paradigmático en este sentido es el concepto de "formantes", desarrollado minuciosamente por Rodolfo Sacco. Véase, SAcco, Rodolfo, Introduzione al diritto comparato, UTET, Torino, 1992, pp. 43-64; Palazzo y PaPA, cit. (n. 10), pp. 43-44; Somma, cit. (n. 45), pp. 153-158.

${ }^{47}$ Véase, recientemente, Fiandaca, Giovanni, Prima lezione di diritto penale, Laterza, Roma, 2017, pp. 126-135; DoninI, cit. (n. 18), pp. 1865-1866; todavía más categórico, DonINI, cit. (n. 4), pp. 34-35, donde afirma: "(h)oy en día no hay operador práctico o teórico serio que crea conocer el Derecho sin conocer la jurisprudencia". En este sentido, a propósito del problema suscitado por ciertas causas de justificación, véase el excelente estudio crítico de ForNASARI, Gabriele, "Diritto giurisprudenziale e cause di giustificazione nell'esperienza tedesca", en: FiandaCA, G. (ed.), Sistema penale in transizione e ruolo del diritto giurisprudenziale, Cedam, Padova, 1997, 21-54.

${ }^{48}$ Entre otros, KINDHÄUSER, cit. (n. 8) p. 17, propone replantear las relaciones entre Dogmática y jurisprudencia.

${ }^{49}$ Somma, cit. (n. 45), p. 44; Palazzo y PAPA, cit. (n. 10), p. 42. Como se sabe, la teoría institucionalista debe al francés Maurice Hauriou (1856-1929) su desarrollo inicial. Sobre esta inteligencia en sus aspectos fundamentales, véase FAssò, Guido, Storia della filosofia del diritto (III. L'età moderna), edición actualizada por Carla Faralli, Laterza, Roma, 2006, pp. 209-210.

${ }^{50}$ Squella Narducci, cit. (n. 33), p. 555; implícitamente, Palazzo y Papa, cit. (n. 10), pp. 35 y 44.
} 
En síntesis, la mirada del comparatista es la de quien, más que el Derecho, indaga la experiencia jurídica tanto en su dimensión empírica como en su esencia de práctica discursiva. Dicho en negativo: la mirada de quien se rehúsa estudiar las normas en sí, abstraídas de la realidad en que se encuentran insertas, prescindiendo del complejo de valores, principios y exigencias que, reconocidos por el Estado, fundamentan (que no suplantan) el orden jurídico. ${ }^{51}$ Eso explica, precisamente, que se opte por fórmulas como experiencia o tradición jurídica, en lugar de "sistema jurídico", más afín a una lectura que acentúa la importancia de la soberanía estatal y que alienta una exaltación nacionalista de las características y tradiciones autóctonas. Las primeras, en cambio, consideran el Derecho como expresión de una cultura, lo que impone prestar atención a las interacciones entre Derecho, sociedad y política, superando así su reducción a mero conjunto de normas referidas a instituciones concretas. El análisis de la experiencia jurídica es el producto de una mirada externa que valora la confluencia entre las normas, ciencia jurídica y, sobre todo, comportamiento humano, que acaba siendo contemplado en su esencia de fuente de preceptos jurídicos. Estos tres mundos, con el continuo tejer y retejer de nuestras relaciones -incluyendo omisiones, trasgresiones y violaciones- concurren a la formación de la experiencia jurídica. ${ }^{52}$ Descifrarla exige poner atención en la complejidad del conjunto de preceptos destinados a condicionar los comportamientos individuales y las relaciones interindividuales, es decir, valorar también las incoherencias y contradicciones de ese conjunto, y confrontar ese resultado con la pretendida coherencia y completitud a que adscribe el positivismo jurídico. En definitiva, una lectura que procura no descuidar la eficacia de los preceptos, esto es, el hecho de que efectivamente constituyan el fundamento que orienta la conducta de los miembros de la sociedad.

A partir de lo anterior se podrá comprender, por ende, que la comparación no se proponga simplemente conocer lo que es distinto a lo propio y describirlo con categorías o un lenguaje comprensible para el lector local, sino que aspira a operar como un método de contraste y diálogo discursivo entre ordenamientos. Por eso es particularmente severa con la comparación que se reduce al análisis de una experiencia extranjera, más

\footnotetext{
${ }^{51}$ DE Rivacoba y Rivacoba, Manuel “¿Una nueva disciplina jurídica? El pretendido 'Derecho de menores", Revista Universidad (U. Nacional del Litoral), 1962, № 51, p. 267. Contradictorio, sin embargo, en p. 272, cuando afirma que el Derecho comparado "trabaja únicamente con normas, no con teorías, principios o métodos científicos".
}

${ }^{52}$ Somma, cit. (n. 45$)$, pp. 40-42. 
todavía si en esa comparación se advierte falta de reciprocidad, pues en ella incuba el indeseable riesgo de asimilación según sean las fortalezas o debilidades del país desde donde se practica la comparación. ${ }^{53}$ En su versión más elaborada, la comparación jurídica no se obliga a mantenerse necesariamente dentro la tradición dogmática que nos es común. Más allá de tener en primera consideración factores de índole cultural, es precisamente la ausencia de estos límites la que le permite formularse interrogantes que al penalista, en cambio, le son particularmente incómodos. Lo dicho a propósito del valor que puede concederse al Derecho jurisprudencial es sólo una muestra de esto; a ella se puede añadir la pregunta en torno a las causas que nos mantienen atados al complejo lenguaje de la Dogmática alemana y que nos impide, por el contrario, partir de estructuras conceptuales y categorías más simples -piénsese, por ejemplo, en el binomio objetivosubjetivo- o de principios jurídicos constitucionales o de política-criminal más afines a nuestra realidad.

\section{Derecho comparado como método de la Dogmática.}

$\mathrm{Si}$, por un lado, la tarea desarrollada por la Dogmática implica evaluar la compatibilidad entre el Derecho penal vigente y la estructura normativa de la sociedad y, por otro, la comparación presupone la valoración, cabe preguntarse sobre la clase de relación epistemológica que existe entre el Derecho comparado y la Dogmática jurídico-penal. ${ }^{54}$ Dicho en otros términos: si la Dogmática debe analizar la autocomprensión normativa de la época y reconducir los principios guía de las normas jurídico-penales y de las reglas de imputación al fundamento que las legitima, ${ }^{55}$ el tipo de relación que ésta mantiene con el recurso comparado no parece ser tan nítido. Pues, como vimos, es impropio hablar de Derecho comparado si la cuestión de la valoración no integra su definición y es, en cambio, degradada a una mera función de carácter contingente. ${ }^{56}$ Independientemente del propósito

\footnotetext{
${ }^{53}$ Donini, cit. (n. 4), pp. 45 y 47.

${ }^{54}$ Advirtió la pertinencia de esta cuestión, concediéndole autonomía científica al Derecho comparado, RadBruch, Gustav, Sul metodo comparativo, trad. it. Rocco Favale, Rassegna di diritto civile, 1997, $\mathrm{N}^{\mathrm{o}} 2$, p. 480.

${ }^{55}$ Así, recientemente, KInDHÄUSER, cit. (n. 8), pp. 16 y 17. Para el autor entre los diversos países varía sólo el contenido de una estructura (teoría del delito) que es, en cambio, universal (cfr. p. 40). CADOPPI, cit. (n. 10), p. 97.

${ }^{56}$ AmBos, cit. (n. 6), p. 12, se refiere así al llamado "Derecho comparado evaluativo-competitivo";
} 
específico que busque la comparación jurídica -orientar al legislador de la reforma o al juez-, ésta necesariamente presupone situar la institución, norma o problema analizado al interior de un contexto jurídico y cultural. Sintéticamente dicho, si el objeto determina el método y aquél no se circunscribe a la (reproducción de la) norma extranjera, su aproximación -el método- se ve necesariamente enriquecida. ${ }^{57}$

Si se adscribe a la tesis conforme a la cual la Política-criminal no es más que el aspecto crítico y momento dinámico de la Dogmática-que evita que mute en dogmatismo o exégesis-, ésta será por definición valorativa, independientemente si, en el caso concreto, se ha tenido que recurrir a la experiencia jurídica extranjera para desatar un nudo u orientar una respuesta. La comparación se erige, en esos términos, como un método instrumental que integra la Dogmática (o la teoría general) y los proyectos de reforma; un método útil para reconstruir verdades, categorías, institutos transversales o el mismo diálogo científico. En síntesis, un instrumento que sirve para transparentar núcleos conceptuales transversales, con un propósito ya no sólo cognoscitivo, sino también valorativo y político. ${ }^{58}$

Puesto que la Dogmática jurídico-penal se propone interpretar un ordenamiento punitivo dado y reconstruir científicamente las diferentes instituciones que hic et nunc integran ese Derecho y edificar a partir de eso un sistema coherente y acabado de conceptos que se corresponda fielmente con él, ${ }^{59}$ la reflexión en torno a lo que sobre una norma, institución o problema específico se ha sostenido en el extranjero bien puede ser considerado (sólo) un importante recurso argumentativo, un método, es decir, una vía intelectual con la que se puede penetrar en un objeto. ${ }^{60}$ Pues, no obstante el hecho de que la Dogmática jurídico-penal sea una proyección acotada de una ciencia cultural, aquélla lo es siempre y únicamente de este o aquel ordenamiento, no siendo factible trasladar y aplicar sin más los conocimientos sobre uno concreto a otro diverso. Ese traslado y aplicación ha de llevarse a cabo, en consecuencia, teniendo muy en cuenta las peculiaridades que singularizan cada ordenamiento y lo distinguen de

Palazzo y PAPA, cit. (n. 10), se refieren a la "comparación con fines meramente cognoscitivos e informativos", pp. 36-38. CADOPPI, cit. (n. 10), p. 95, plásticamente, alude al "giornalismo giuridico".

${ }^{57}$ Así, aludiendo una especie de pluralismo metodológico, DoninI, cit. (n. 18), p. 1865.

${ }^{58}$ Cfr., por todos, Donini, cit. (n. 18), pp. 1863-1864.

${ }^{59}$ Así, entre otros, KINDHÄUSER, cit. (n. 8), p. 31.

${ }^{60}$ Así, Ambos, cit., (n. 6), p. 23. 
los demás. ${ }^{61} \mathrm{Y}$ el método comparativo, a su vez, puede acompañar a la Dogmática jurídico-penal cualquiera sea el enfoque -histórico, filosófico, científico y crítico- que adopte al afrontar un problema determinado. En esos términos, la comparación funge como un método de la Dogmática, como un elemento que aporta a su cientificidad. No detenta, como cree ver un sector minoritario, autonomía científica por la mera circunstancia de proponerse conocer mejor el Derecho o por compartir el mismo criterio de validez de la Historia, en el sentido analizar fenómenos jurídicos pasados y presentes conforme a determinados criterios. ${ }^{62}$ Indiscutiblemente, la comparación robustece desde un punto de vista epistemológico la interpretación, tanto en lo que se refiere a la comprensión misma del precepto, como en su crítica y eventual corrección legal, pero sigue detentando una presencia contingente en la actividad dogmática. Así, con mucha probabilidad, la presencia del recurso comparado se manifestará con mayor intensidad en la Parte general, que es -por así decirlo- más "científica" que la regulación contenida en la Parte especial o en leyes complementarias, normalmente condicionada por la contingencia de lo político. ${ }^{63}$

El desarrollo de la comparación al interior de la Dogmática presupone, en definitiva, la superación del paradigma del Derecho cual norma abstracta y la pretendida neutralidad axiológica del saber científico que infravalora la actividad del intérprete; es decir, de la concepción que, concediendo una fe ciega a la autoridad, atiende nada más que a la estructura lógica del Derecho y a su pretendida coherencia y perfección formal, soslayando el carácter cultural, humano y, por ende, imperfecto de éste. ${ }^{64}$ En una palabra, el conceptualismo.

\footnotetext{
${ }^{61}$ De Rivacoba y Rivacoba, cit. (n. 23), pp. 38, 41, 257 y 263. En términos análogos, Bonini, Sergio, "Sulla tutela penale di vittime fragili", L'indice penale, 2014, No 2, pp. 692-693.

${ }^{62} \mathrm{Cfr}$. por todos, SACCO, Rodolfo, cit. (n. 46), pp. 10-18, paradigmático representante de la llamada "tesis de Trento". En un sentido análogo, sin perjuicio de lo que ha afirmado en otros trabajos (cfr. n. 4, p. 46), DoninI, cit. (n. 14), p. 177, afirma que "(1)a Historia y la comparación configuran un momento de verificación decisivo, y también una importante calificación para la misma Dogmática y no una alternativa a esta última". La cursiva es nuestra.

${ }^{63}$ Así, Donini, Massimo, "Scienza penale e potere politico", Rivista italiana di diritto de procedura penale, 2015, No 1, p. 121. Véase lo dicho en cit. (n. 25).

${ }^{64}$ Así, según nuestro parecer, HruschKa, cit., (n. 31), p. 254, para quien uno de los postulados de la sistematicidad de la Dogmática es que "(e)ntre las correspondientes proposiciones o conceptos de la teoría que se hallan conectados, y que poseen distinto rango, debe existir una relación de derivación (Ableitungsverhältnis); y ésta debe presentarse, o debería poder presentarse, con exactitud". Críticos respecto de esta y otras formas análogas de ver el asunto: DE RivacoBa y RivacoBa, Manuel, División y fuentes del Derecho positivo, Edeval, Valparaíso, 1968, p. 151; NovoA Monreal, Eduardo, Alternativas
} 
Cuando el dogmático decide utilizar el método comparativo, es preciso que ab initio tenga claro por qué emplea dicho recurso. Además, lo coherente será que transparente las razones de esa decisión metodológica. Y esto por un doble motivo. En primer término, porque la más moderna deontología de las ciencias sociales enseña que sólo precisando el objeto de estudio y los objetivos cognitivos que persigue el estudioso, será posible seguir reglas metodológicas rigurosas para delimitar el ámbito de la investigación o elegir los casos o institutos que se examinarán. En segundo lugar, porque hacerlo constituye un gesto de honestidad intelectual: dado el carácter marcadamente orientado y selectivo del análisis comparado -que estudia, por ejemplo, sólo un instituto o confronta sólo unos pocos sistemas de entre varios existentes-, es indispensable prevenir al lector para que pueda sopesar los condicionamientos derivados del propósito de la investigación. Una cosa, en efecto, es comparar con un propósito puramente didáctico o informativo y otra, muy distinta, es comparar para promover una reforma o estimular la creación de instrumentos de armonización entre diversos países. ${ }^{65}$

\section{UNA MUESTRA DE INVERSIÓN METODOLÓGICA: EL ESTADO DE NECESIDAD}

Las teorías dogmáticas pueden considerarse inaceptables si ellas incurren, más o menos abiertamente, en contradicciones de valor, desconocen el tenor literal de la ley, ignoran sistemáticamente contextos o si llevan a resultados que simplemente desvían la finalidad de la norma. ${ }^{66}$ En buena medida, esto es lo que ha ocurrido con la discusión local del estado de necesidad justificante. En ella se aprecia, a la luz de cuanto hemos examinado, un descuidado modo de hacer comparación jurídica.

y trances del derecho penal de hoy, Anuario de Derecho Penal y Ciencias Penales, 1978, Fascículo III, pp. 533-534. Más recientemente, Guzmán Dalbora, José Luis, Elementi di filosofia giuridicopenale, (Fornasari, G. y Macillo, A., Eds.) Universita degli studi di Trento, Trento, 2015, p. 150; sobre la actitud de la academia alemana frente a las decisiones del legislador, véase el severo juicio comparativo de DonINI, cit. (n. 4), pp. 42-43.

${ }^{65}$ Palazzo y PAPA, cit., (n. 10), p. 46. En la doctrina chilena repara en esto, en passant, LondoÑo Martínez, Fernando, "El caso de la 'llave de gas del frustrado suicida-parricida': sobre la punibilidad de la tentativa con dolo eventual", en: VArgas, T. (ed.), Casos destacados. Derecho penal. Parte general, Thomson Reuters, Santiago, 2015, pp. 232-234 y 254-255.

${ }^{66}$ Así, KinDHÄUSER, cit. (n. 8), p. 37. 
Tradicionalmente la tesis de la doctrina local consistió en asumir que el fundamento de esta causa de justificación era el llamado principio del interés preponderante. Tras la reforma que en 2010 experimentó el Código penal -que introdujo explícitamente el instituto en su versión exculpante-, buena parte de la doctrina local, inclinada por una tendencia de larga data en Alemania, ${ }^{67}$ comenzó a adscribir, en cambio, a la tesis del principio de solidaridad, cuyo desarrollo, sin embargo, se explica por a lo menos dos condiciones - una jurídica y otra política- que en Chile no se presentan. En primer lugar, la inexistente distinción, tanto en lo penal como civil, entre estado de necesidad justificante agresivo y defensivo. El origen y desarrollo de la tesis de la solidaridad, en efecto, se explica por la minuciosa regulación civil del instituto en Alemania y por la entonces débil regulación penal del mismo, que se limitaba a reconocer sólo la versión exculpante. Como se sabe, en nuestro país el estado de necesidad civil constituye una institución reconocida sólo por la jurisprudencia, no por la ley ${ }^{68}$ Por lo demás, la clase de conflictos de los que se hace cargo el instrumento penal son distintos a los que hace frente el Derecho civil. Si se considera los bienes jurídicos cuya tutela es confiada a esta rama del ordenamiento, deviene comprensible que el deber de tolerancia que nace para el tercero que no ha contribuido a crear el contexto de necesidad, se identifique con la idea de solidaridad; máxime si en esta sede -a diferencia de lo que ocurre en Derecho penal- el concepto nunca ha sido histórica o políticamente controvertido. ${ }^{69}$ Precisamente desde esta perspectiva, el debate civil es ciertamente menos espinoso que el punitivo. El Derecho civil, dado su tradicional e histórico objetivo, está provisto de instituciones -piénsese en el enriquecimiento sin causa como fuente de las obligaciones- que permiten lidiar más fácilmente con la idea de la invasión de esferas ajenas inocentes. ${ }^{70}$

\footnotetext{
${ }^{67} \mathrm{La}$ tesis, naturalmente, ha sido fruto de desarrollos ulteriores mucho más finos y acabados (piénsese, por ejemplo, en las monografías de Renzikowski y Pawlik), pero un primer antecedente es posible reconocerlo ya en HeInItz, Ernst, Das problem der materiellen Rechtswidrigkeit, Keip, Breslau, 1926, reimpresión de 1977, pp. 37-38.

${ }^{68}$ Cfr., por todos, VIAL del Río, Víctor, Teoría general del acto jurídico, Editorial jurídica de Chile, Santiago, 2006, pp. 113-115.

${ }^{69}$ Una síntesis se encuentra en AlCÁCER GuIrao, Rafael, "Autonomía, solidaridad y deber de socorro", Anuario de Derecho Penal y Ciencias Penales, 2000, T. LIII, pp. 365 y ss.; y Varona Gómez, Derecho penal y solidaridad. Teoría y práctica del mandato penal de socorro, Dykinson, Madrid, 2005, 19-20. ${ }^{70}$ Lo que explica que muchos ordenamientos, como el alemán e italiano, prevean el derecho del propietario agredido a ser resarcido pecuniariamente. Véase, Mezzetti, Enrico, "Necessitas non habet legem?" Sui confini tra "impossibile ed "inesigibile" nella struttura dello stato di necessità,
} 
El carácter científico de la Dogmática, junto a la racionalidad de su procedimiento, también se juega en el tejido de conexiones extensas y sistemáticas con otras ramas del Derecho, lo que exige -como ocurre en este caso- considerar también sus eventuales vacíos. ${ }^{71}$ Según se aprecia, al menos desde esta perspectiva, la condición mínima para extrapolar una teoría de estas características a la realidad chilena es una cierta similitud del cuadro normativo que se interpreta. Como ha sido razonablemente afirmado, si la actividad dogmática pierde de vista el Derecho de origen, la construcción teórica podrá tener valor filosófico, antropológico o histórico, pero un interés jurídico relativo. ${ }^{72}$ Sin embargo, a juzgar por el tono con que se ha internalizado en nuestra discusión la idea de la solidaridad, es posible conjeturar que sus defensores no buscan simplemente satisfacer una curiosidad intelectual; persiguen algo más que saber cómo se tratan determinados problemas fuera de nuestra frontera y así apreciar mejor las bondades y defectos del sistema jurídico nacional.

En segundo lugar, esta lectura prescinde de las buenas razones que asisten para negar que el Estado chileno tenga carácter solidario y que permitan, a su vez, insinuar que la exigencia de inactividad del tercero inocente responda a algo así como un deber de solidaridad al que estaríamos obligados a favor del prójimo. ${ }^{73}$ Así como ocurre en otros ámbitos, la discusión local sobre el estado de necesidad se ha caracterizado por prescindir de toda referencia extraída de la Historia y Filosofía del Derecho. ${ }^{74}$ Esta omisión, además, es particularmente notoria si se repara en que el tipo de materias examinadas por la comparación en el ámbito del Derecho público, guarda relación, precisamente, con las formas de Estado o los modelos de

\footnotetext{
Giappichelli, Torino, 2000, p. 216.

${ }^{71}$ Similar, KINDHÄUSER, cit. (n. 8), p. 35.

${ }^{72}$ VAN WeEZel, cit. (n. 5), p. 4.

${ }^{73}$ Lo advierte explícitamente, con referencia a las llamadas teorías "decisionistas" de la solidaridad, Wilenmann von Bernath, Javier, "El fundamento del estado de necesidad justificante en el derecho penal chileno", Revista de Derecho (Valdivia), 2014, Vol. XXVII, No 1, p. 236. Sin embargo, no queda del todo claro cómo la línea teórica suscrita por autor, a saber, la solidaridad entendida en términos institucionales (cfr. pp. 237-238), se liberaría de esta objeción, máxime si él mismo reconoce que ésta también asume (como hacen las teorías decisionistas) la existencia de una obligación estatal de corregir situaciones de necesidad, sólo que en este caso dicha corrección es delegada a la persona natural que termina padeciendo las consecuencias de la acción necesaria.

${ }^{74}$ Defecto que compartiría, en general, parte ostensible la producción jurídica nacional, como afirma una autorizada voz de la ciencia jurídica nacional, según registra Squella NARducci, cit. (n. 33), p. 566. Véase, en lo que se refiere al campo penal, de Rivacoba y Rivacoba, cit. (n. 25), p. 116.
} 
organización judicial y administrativo. ${ }^{75} \mathrm{La}$ insistencia con la tesis de la solidaridad, además, deviene todavía más forzada porque soslaya un dato tan cierto como desolador, esto es, la supresión por parte de la dictadura pinochetista de "todo vestigio de fraternidad entre los chilenos" y la exitosa instauración a nivel de relaciones sociales "no tanto (de) la mentalidad unidimensional del homo xeconomicus (...), sino (del) oportunismo de las aves de rapiña" ${ }^{76}$ Un planteamiento de este tenor olvida que para juzgar un Derecho o, más en general, una cultura jurídica determinada, es necesario conocer el conjunto de condiciones, creencias, puntos de vista, modos de sentir, de pensar y de actuar que respecto de ese Derecho prevalecen en esa comunidad. El hecho de que la omisión de deber de socorro - no sin razón vista como la contrapartida de este deber tolerancia - sea sólo una falta sancionada con una multa, es un agudo reflejo del significado que nuestra legislación atribuye a la idea de solidaridad. ${ }^{77}$

En definitiva, lo que se aprecia en este caso es una flagrante inversión metodológica. Se parte de la base de que la Dogmática se ocuparía de algo distinto de la ley; por el contrario, es ésta la que debería someterse a teorizaciones caracterizadas, aparentemente, por poseer un alcance universal. ${ }^{78}$ Es lo que también ocurre, por ejemplo, con la tesis alemana que niega distinción entre antijuridicidad y culpabilidad a pesar de la distinta naturaleza de las instituciones que subyacen en los conocidos $\S \S 34$ y 35 del StGB. ${ }^{79}$

En el caso que hemos descrito, la idea de la solidaridad sería de una abstracción tal que podría perfectamente adaptarse a otros sistemas jurídicos.

\footnotetext{
${ }^{75}$ Así, Somma, cit. (n. 45), p. 47.

${ }^{76}$ Así, recientemente, GuZmÁn DALbora, José Luis, "Las concepciones filosófico-jurídicas de Eduardo Novoa Monreal”, en: Ambos, K., Guzmán Dalbora, J.L., Derecho y cambio social. Estudios críticos en homenaje a Eduardo Novoa Monreal, Der-Edeval, Santiago, 2018, p. 156, nota 43. La tesis de que antes del comienzo de la dictadura existía sólo un vestigio es implícitamente ratificada por NovOA Monreal, Eduardo, "Bases para una reforma en el área de las Ciencias Jurídicas (1969)", en: Centro de Estudios Políticos Latinoamericanos Simón Bolívar (eds.), Obras escogidas. Una crítica al Derecho tradicional, Ediciones del Centro de Estudios Políticos Latinoamericanos Simón Bolívar, Santiago, 1993, p. 402.

${ }^{77}$ Véase, recientemente, Rojas AguirRe, Luis Emilio, "El reducido espacio de la solidaridad en la Parte especial del Derecho penal chileno", Revista de Derecho (Valdivia), 2019, Vol. XXXII, N 1 , pp. 295-310.

${ }^{78}$ Adscribe abiertamente a esta lectura, HrUSCHKA, cit. (n. 31), pp. 270-271, para quien dicho objeto es el concepto de "lesión imputable del deber", ante el cual la ley no desempeñaría ningún papel. Postura que no es distinta de la que algunos, críticamente, han denominado "principialismo político-criminal". Así, Mañalich Raffo, cit., (n. 32), p. 60.

${ }^{79}$ Así, por ejemplo, Pawlik, Michael, Ciudadanía y derecho penal, Atelier, Barcelona, 2016, p. 135.
} 
Sin embargo, los inconvenientes de este proceder son evidentes, pues asumen un concepto de Dogmática despojado de su función (primordial) de indicarnos el contenido del Derecho positivo y las soluciones para interpretarlo. Por otra parte, y a pesar de su alta adaptabilidad, universalidad o abstracción, una aproximación de este tenor no garantiza -contrariamente a cuanto se podría intuir- la predictibilidad de la solución en el caso concreto, pues los puntos de partida quedan entregados al arbitrio del teórico de que se trate. ${ }^{80}$

Conviene tener presente, en todo caso, que esta reserva metodológica no implica necesariamente una objeción de fondo respecto de la idea misma de solidaridad. Independientemente del contenido específico que se le atribuya, nada impide que al interior de una comunidad varíen las estimaciones y preferencias que erigen los valores predominantes y que perfilan sus reglas de conducta. Una de las grandes dificultades con las que debe lidiar el dogmático es, de hecho, que unas y otras se alteran y suceden continuamente. ${ }^{81}$ No obstante, y respaldado por ese cambio cultural en las valoraciones, el dogmático podrá perfectamente combatir, tanto en el plano teórico como interpretativo, la presencia en la legislación de instituciones que puedan responder a una antropología individualista. Antes que eso ocurra, cualquier remisión a la discusión extranjera sin contextualización del dato cultural, es apresurada. Incluso dando por cierto el nulo tratamiento local de esta materia, el mero hecho que en Alemania se hayan verificado notables avances, no es razón suficiente para importarlos in toto. ${ }^{82}$ De haber tenido presente lo anterior, probablemente la discusión habría partido con un intento por explicar por nosotros mismos este tópico o, incluso, haber tenido a la vista realidades políticas y culturales más afines a la nuestra. En esos términos, queda mediamente claro que determinante no será el momento o el lugar de origen de una teoría o idea, sino su capacidad explicativa (y predictiva) del funcionamiento de nuestro sistema penal. ${ }^{83}$

\footnotetext{
${ }^{80}$ Así, Matus AcuÑa, cit. (n. 5), p. 8, 11, 13 y 14; similar, Donini, cit. (n. 4), p. 40.

${ }^{81}$ DE RivacoBa y RivacoBa, cit. (n. 25), p. 113.

${ }^{82}$ Así, en cambio, Wilenmann von Bernath, cit. (n. 72), pp. 220 y 222. En nuestra interpretación del argumento, es imprecisa la afirmación según la cual la teoría del interés preponderante constituiría un lugar común entre los penalistas chilenos. Si bien acá no podemos adentrarnos en este punto, en nuestra opinión sí es posible reconocer en ella herramientas conceptuales que, debidamente leídas, reflejan el andamiaje filosófico y conceptual de lo que prematuramente se asume como un lugar común.

${ }^{83}$ Cfr. Matus Acuña, cit. (n. 5), pp. 21-23; van Weezel, cit. (n. 5), p. 4.
} 
V. CONSIDERACIONES CONCLUSIVAS: HACIA UN MÉTODO CIENTÍFICO MODERNO

A partir de cuanto se ha señalado, se perfila un cierto modo en que la Dogmática jurídico-penal debe comenzar a relacionarse con saberes y disciplinas que tradicionalmente ha denominado auxiliares. El momento actual, por lo demás, es bastante propicio para desdramatizar una apertura en este sentido, pues ni siquiera las ciencias naturales adscriben hoy a un monismo metodológico. ${ }^{84}$ Esta nueva actitud debe partir de la premisa de que, si bien fundamental e insustituible, el discurso dogmático es sólo uno de los variados discursos que deben integrarse reflexivamente en pos de una teorización comprensiva de los sistemas penales contemporáneos. ${ }^{85} \mathrm{Sin}$ embargo, se trata de un cambio de perspectiva que exige superar una serie de obstáculos, comenzando por la seducción que genera la exactitud y precisión del método hermenéutico propio del neopositivismo. Es indispensable, asimismo, corregir el injustificado (pero difundido) prejuicio según el cual en torno al deber ser queda excluida toda consideración fáctica. La integración interdisciplinaria, en fin, se verá fuertemente favorecida si la academia logra evitar la frecuente reacción del poder político-legislativo cuando irrumpe con conocimientos que se oponen al discurso criminalizador hegemónico. ${ }^{86}$

Una mirada más atenta, sin embargo, convence de cuan artificial es este estado de cosas. La historia del Derecho penal demuestra, por el contrario, que nuestra disciplina nunca ha sido -por así decirlo- pura en términos kelsenianos. Por el contrario, la contaminación política, sociológica, criminológica y filosófica ha sido indispensable para su desarrollo, como también su necesidad de orientarse hacia la praxis y no anclarse en el conocimiento abstracto del Derecho. Desde siempre, aunque con diversos niveles de transparencia, ha abrazado sectores altamente

\footnotetext{
${ }^{84}$ En detalle, Donini, cit., (n. 63), p. 115-116; Perin, Andrea, "Conocimientos científicos, tecnologías convergentes y Derecho penal", en: Romeo, C. (ed.), Tecnologías convergentes: desafíos éticos y jurídicos, Comares, Granada, 2016, pp. 145-148 y 173-174.

${ }^{85}$ Así, recientemente, MaÑalich Raffo, cit. (n. 32), p. 67; similar, CAdoppi, Alberto, Veneziani, Paolo, Elementi di diritto penale, Parte generale, Cedam, Padova, 2007, 3 ${ }^{\mathrm{a}}$ ed., pp. 10 y 13.

${ }^{86}$ Véanse las agudas reflexiones autocríticas de SEminara, Sergio, "Divagazioni sulla nozione di accademia", Diritto Penale Contemporaneo, 2018, n 4, versión .pdf, disponible en línea: https:// www.penalecontemporaneo.it/d/6223-divagazioni-sulla-nozione-di-accademia (visitada al 1 de julio de 2019), pp. 5-7.
} 
diferenciados metódica y epistemológicamente. ${ }^{87}$ Como gráficamente ha sido enfatizado, el progreso en el campo jurídico y moral es en buena parte fruto de la revelación empírica de los errores (y aberraciones) acerca de las condiciones biológicas, antropológicas y sociales del ser humano. La adscripción de cualidades institucionales jurídico-penalmente relevantes es inútil cuando la afirmación de los correspondientes hechos primarios es falsa o deficiente. Que una persona cuente como capaz de culpabilidad, por ejemplo, es una cualidad secundaria frente a sus cualidades naturales primarias; por eso, la adecuada comprensión de la realidad empíricamente cognoscible es un presupuesto necesario de la adecuada constitución de los hechos jurídicos. ${ }^{88}$

A mayor abundamiento, la falta de integración disciplinaria se vuelve todavía más inexplicable si se repara en el gran déficit con que debe lidiar la Dogmática: la acientificidad de las decisiones del legislador. El desprecio legislativo por saberes como la Criminología o, en general, del conocimiento empírico, es directamente proporcional al riesgo de terminar idealizando al Derecho penal. ${ }^{89}$ Ante las consecuencias que acarrearía esto, el reto hacia una apertura y un incremento del saber empírico pasa, prioritariamente, por su entrada en la fase de creación y diseño legislativo y no sólo en la etapa de interpretación y ejecución del tipo penal. Sin una legislación basada en esta clase de conocimiento, el papel de la ciencia penal podrá ser crítico, pero con escasa capacidad explicativa de las consecuencias, toda vez que el proyecto legislativo ni siquiera las imagina o conoce. Bien visto el asunto, resistirse a la entrada del conocimiento empírico, implica asumir que la función preponderante del Derecho penal -y que debe continuar desarrollando de manera esencial o exclusiva- es de carácter simbólico, es decir, de mera reafirmación de valores en la conciencia colectiva. ${ }^{90}$

El propio caso del estado de necesidad, por ejemplo, es una óptima oportunidad para aprovechar las posibilidades que permite la orientación constitucional del Derecho penal. A diferencia de lo que ocurre con la Dogmática clásica, la lectura constitucional de los institutos penales ha

\footnotetext{
${ }^{87}$ Donini, cit. (n. 18), p. 1865.

${ }^{88}$ KINDHÄUSER, cit. (n. 8), pp. 18-19 y 40-41.

${ }^{89}$ Así, en otros términos, Mañalich RAFFo, cit. (n. 32), p. 61.

${ }^{90}$ Donini, cit. (n. 4), p. 28 y 49-50. Sobre la función simbólica del Derecho penal como rasgo diferenciador de la disciplina, véase, recientemente, BonINI, Sergio, La funzione simbolica nel diritto penale del bene giuridico, Editoriale Scientifica, Napoli, 2018, pp. 187-194.
} 
dado lugar a una etapa de pluralismo de los actores jurídicos, pues las constituciones interpelan de igual manera a legisladores, jueces, abogados y estudiosos. De este modo, seguramente, se contribuirá a que el método dogmático sea menos aristocrático, y transite, en cambio, hacia uno más dialéctico y discursivo. Al involucrar a toda la sociedad jurídica y sus instituciones, la Dogmática no será sustituida, sino que se enriquecerá y renovará. Es precisamente desde esta óptica que ha comenzado a ganar terreno en los países desarrollados la investigación grupal como paradigma de trabajo. Las ventajas de este proceder se traducen en una disminución del muchas veces lenguaje personalizado de los juristas y en una mayor atención a los datos cuantitativos, estadísticos y empíricos. En lo que se refiere a la comparación, el trabajo en equipo implica necesariamente la necesidad de que ésta no quede entregada a la iniciativa y al conocimiento lingüístico de cada estudioso, sino que constituya un instrumento indispensable para un diálogo desarrollado en condiciones de reciprocidad..$^{91}$

La comparación, según vimos, impone considerar las razones históricas y sociales que llevan a un país a adoptar una determinada solución normativa. Esa tarea, como es evidente, trae aparejada una notable complejidad para el jurista, pues los factores que pueden haber incidido en ella suelen ser múltiples y de diversa naturaleza (históricos, de simple tradicion, políticos, de carácter contingentes, etc.); si se quiere evitar que el penalista "improvise" cual historiador, sociólogo o filósofo del derecho, es indispensable partir de la base de que una jerarquía epistemológica entre las distintas disciplinas no existe. Como deslizamos previamente, para el penalista se tratará de una tarea sumamente compleja, no sólo por la falta de herramientas heredada de la formación tradicional, sino por las incertezas que emergerán para la Dogmática, comenzando por las asociadas a las fuentes del Derecho penal. ${ }^{92}$ La tarea, en esos términos, impondrá transparentar el aislamiento crónico que padece la Dogmática y que ha obstruido todo diálogo con la Criminología, Sociología y Política jurídica. ${ }^{93}$

Si bien en el ámbito nacional una apertura en este sentido es todavía incipiente, es reconfortante que una autorizada voz del Derecho penal italiano, perteneciente, como se sabe, a una generación ya madura, de cuenta que el método de la Ciencia penal esté condicionado a ser el llamado "método

\footnotetext{
${ }^{91}$ Donini, cit. (n. 4), pp. 48-49 y 51; Donini, cit. (n. 14), pp. 157-158.

${ }^{92}$ Palazzo y Papa, cit. (n. 10), pp. 35 y 40-41.

${ }^{93}$ Squella Narducci, cit. (n. 33), p. 578.
} 
científico moderno", cuyo carácter pluridimensional y libre apriorismos, indaga por medio de distintas aproximaciones científicas una realidad articulada, es decir, a través de aproximaciones parciales que, cada una con su propio objeto y método, precisan de integraciones interdisciplinarias, volviéndolas -Dogmática incluida- conscientes de la relatividad de las propias conquistas y de su perenne carácter problemático. ${ }^{94}$

La cuestión, en nuestra óptica, pasa por esta apertura interdisciplinaria y no -o no solamente, al menos-, por el abandono de la Dogmática tradicional (y del papel que en ella juega el saber empírico) por un Derecho penal orientado al análisis y estudio de casos. ${ }^{95}$ La apertura interdisciplinaria sigue siendo compatible con la afirmación de que sólo un estudio cuya matriz está desvinculada de los casos particulares permite identificar soluciones de valor y alcance general. ${ }^{96}$ Lo determinante será que en esta redefinición la Dogmática -no desprendiéndose de su proceder deductivo y teleológico $-{ }^{97}$ se libere de la permanente amenaza conceptualista, cuyo intransigente formalismo le impide apreciar que su destinatario y razón de ser es el hombre o mujer que espera el veredicto del juez.

\section{BIBLIOGRAFÍA CITADA}

\section{a) Doctrina citada}

AlCÁCer Guirao, Rafael, "Autonomía, solidaridad y deber de socorro", Anuario de Derecho Penal y Ciencias Penales, 2000, T. LIII, pp. 361-411.

Амвos, Kai, "Estado y Futuro del Derecho Penal Comparado", Revista Penal (España), 2018, № 41, pp. 5-26.

Amisano, Maristella, Le esimenti non codificate. Profili di liceità materiale, Giappichelli, Torino, 2003.

ANCEL, Marc "Reflexiones sobre estudios de Derecho comparado", en: JimÉnez, M. (ed.), Problemas actuales de las Ciencias penales y la Filosofía del

\footnotetext{
${ }^{94}$ Mantovani, cit. (n. 18) pp. 35 y 36, donde afirma que los estudios histórico-comparados son insustituibles, pues "fuera de la historia y de la comparación no hay auténtica 'cultura jurídica"'. Desde la vereda de los comparatistas, en idénticos términos, Somma, cit. (n. 41).

${ }^{95}$ Así, Ambos, cit. (n. 6), p. 19.

${ }^{96}$ Así, Donini, cit. (n. 18), p. 1871.

${ }^{97}$ Por todos, Pulitanò, cit. (n. 27), p. 10.
} 
Derecho, Homenaje a Luis Jiménez de Asúa, Pannedille, Buenos Aires, 1970, pp. 601-619.

BACigAlupo Zapater, Enrique, "La recepción de la dogmática penal alemana en España y Latinoamérica", InDret, 2019, $\mathrm{n}^{\circ}$ 2, pp. 1-21, disponible en línea: http://www.indret.com/pdf/1458.pdf (7 de mayo de 2019).

BonInI, Sergio, "Sulla tutela penale di vittime fragili”, L'indice penale, 2014, $\mathrm{N}^{\mathrm{o}} 2$, pp. 667-699.

BoninI, Sergio, La funzione simbolica nel diritto penale del bene giuridico, Editoriale Scientifica, Napoli, 2018.

Bricola, Franco, "Teoria generale del reato", en: Canestrari, S., Melchionda, A. (eds.), Scritti di Diritto penale, Vol. I, T. I, Giuffrè, Milano, 1997.

Bricola, Franco, "Relaciones entre Dogmática y Política criminal", Revista de Derecho penal y Criminología (Buenos Aires), 2015, No 10.

Cadoppi, Alberto; Veneziani, Paolo, Elementi di diritto penale, Parte generale, Cedam, Padova, 2007, $3^{\mathrm{a}}$ ed.

CADOPPI, Alberto, Tra storia e comparazione. Studi di diritto penale comparato, Cedam Padova, 2014, p. 94.

Cury Urzúa, Enrique, Derecho penal. Parte general, Ediciones Universidad Católica de Chile, Santiago, 2009, 9a ed.

DE Rivacoba y Rivacoba, Manuel “¿Una nueva disciplina jurídica? El pretendido 'Derecho de menores", Revista Universidad (U. Nacional del Litoral), 1962, No 51, pp. 259-294.

DE Rivacoba y Rivacoba, Manuel, División y fuentes del Derecho positivo, Edeval, Valparaíso, 1968.

DE Rivacoba y Rivacoba, Manuel, Elementos de Criminología, Edeval, Valparaíso, 1982.

DE Rivacoba y Rivacoba, Manuel, “Hacia un nuevo conceptualismo jurídico?", Boletín de la Facultad de Derecho, 1998, No 13, pp. 108-119.

Donini, Massimo, "La relación entre Derecho penal y política: método democrático y método científico", Revista de estudios de la Justicia, 2004, N 4, pp. 27-50.

Donini, Massimo, “Tecnicismo giuridico e scienza penale cent'anni dopo. La prolusione di Arturo Rocco (1910) nell'età dell'europeismo giudiziario”, Criminalia, 2011, pp. 127-178.

Donini, Massimo, "Scienza penale e potere politico", Rivista italiana di diritto de procedura penale, 2015, No 1, pp. 95-136.

Donini, "La situazione spirituale della ricerca giuridica scientifica", Cassazione Penale, 2016, Vol. 56, No 5, pp. 1853-1888.

FARALLI, Carla, La filosofia del diritto contemporanea, Laterza, Roma, 2002. 
FAssò, Guido, Storia della filosofia del diritto (III. L'età moderna), edición actualizada por Carla Faralli, Laterza, Roma, 2006.

Fernández Albor, Agustín, "Aportación al estudio comparado de los sistemas penales europeos”, Anuario de Ciencias penales, 1966, T. XIX, Fascículo I, pp. 39-65.

Fiandaca, Giovanni, Prima lezione di diritto penale, Laterza, Roma, 2017.

FornASARI, Gabriele, "Diritto giurisprudenziale e cause di giustificazione nell'esperienza tedesca", en: FiandacA, G. (ed.), Sistema penale in transizione e ruolo del diritto giurisprudenziale, Cedam, Padova, 1997, pp. 21-54.

FORNASARI, Gabriele, "Conquiste e sfide della comparazione penalistica”, en: Dolcini, E.; Paliero, C.E. (eds.), Studi in onore di Giorgio Marinucci. I. Teoria del diritto penale, criminología e Política-criminale, Giuffrè, Milano, 2006, pp. 265 282.

Fornasari, Gabriele, Corn, Emanuele, "Premessa: così lontano ma così vicino: il vecchio codice penale cileno e il diritto penale in Italia oggi", en: Fornasari, G., Corn, E., (eds.), Codice penale della Repubblica del Cile, Cedam, Padova, 2013, pp. IX-XIII.

FORNASARI, Gabriele, "Presentación a 'Relaciones entre Dogmática y Política criminal", Revista de Derecho penal y Criminología (Buenos Aires), 2015, № 10, pp. 27-28.

Guzmán Dalbora, José Luis, "Relaciones del Derecho penal con el Derecho constitucional, y su concreción en la Constitución política chilena (1980)", Anuario de Filosofía Jurídica y Social, 1994, N 12, pp. 165-199.

GuZmán Dalbora, José Luis, "Il codice penale cileno nel prima del tempo", en: Fornasari, G., Corn, E. (eds.) Codice penale della Repubblica del Cile, Cedam, Padova, 2013, p. IX-XXXIV.

Guzmán Dalbora, José Luis, Elementi di filosofia giuridico-penale, (Fornasari, G. y Macillo, A., Eds.) Universita degli studi di Trento, Trento, 2015.

Guzmán Dalbora, José Luis, Cultura y delito, Edeval, Valparaíso, 2018.

Guzmán Dalbora, José Luis, "Las concepciones filosófico-jurídicas de Eduardo Novoa Monreal”, en: Ambos, K., Guzmán Dalbora, J.L., Derecho y cambio social. Estudios críticos en homenaje a Eduardo Novoa Monreal, DerEdeval, Santiago, 2018, pp. 141-186.

HeINITZ, Ernst, Das problem der materiellen Rechtswidrigkeit, Keip, Breslau, 1926, reimpresión de 1977.

HRUSCHKA, Joachim, “¿Puede y debería ser sistemática la dogmática jurídicopenal?", en SÁnchez-Ostiz, P. (dir.), Imputación y Derecho penal. Estudios sobre la teoría de la imputación, Thomson-Aranzadi, Navarra, 2005.

JimÉnez DE AsúA, Luis, Tratado de Derecho penal. Tomo I, Losada, Buenos Aires, 1977, $4^{\mathrm{a}}$ ed., actualizada. 
KindHäUSER, Urs, "Acerca del objeto y la tarea de la ciencia del Derecho penal”, Derecho penal contemporáneo. Revista Internacional, 2019, nº 66 (eneromarzo), pp. 15-45.

Laplaza, Francisco P., "Orígenes y preterición del Derecho penal comparado", en CAlabró, A. (Ed.), Estudios jurídicos en Homenaje al Profesor Luis Jiménez de Asúa, Abeledo Perrot, Buenos Aires, 1964, pp. 520-537.

Londoño Martínez, Fernando, "El caso de la "llave de gas del frustrado suicida-parricida': sobre la punibilidad de la tentativa con dolo eventual", en: Vargas, T. (ed.), Casos destacados. Derecho penal. Parte general, Thomson Reuters, Santiago, 2015, pp. 223-262.

Londoño MarTínez, Fernando, "Idiosincrasia y dogmática penal italiana. De paso, sobre si acaso Franco Bricola fue un revolucionario o un reformador (Un ejercicio poco 'científico', ma con grande affetto)", 22 de marzo de 2019, disponible en línea: http://www.criminaljusticenetwork.eu/es/post/idiosincrasia-y-dogmaticapenal-italiana-de-paso-sobre-si-acaso-franco-bricola-fue-un-revolucionario-o-unreformador-un-ejercicio-poco-cientifico-ma-con-grande-affetto (fecha de consulta: 30 de mayo de 2019).

López Rey Arrojo, Manuel, "Criterios y perspectivas de la codificación penal”, Revista de Derecho penal y Criminología (Buenos Aires), 2012, No 11, pp. 235-243.

Mantovani, Ferrando, Diritto penale. Parte generale, Cedam, Padova, 2016, $9^{\mathrm{a}}$ ed.

Mañalich RafFo, Juan Pablo, "El principialismo político-criminal como fetiche", Revista de Estudios de la Justicia, 2018, № 29, pp. 59-71.

Matus AcuÑa, Jean Pierre, "El positivismo en el derecho penal chileno. Análisis sincrónico y diacrónico de una doctrina de principios del siglo XX que se mantiene vigente", Revista de Derecho (Valdivia), 2007, Vol. XX, No 1, pp. 173203.

Matus AcuÑa, Jean Pierre, "Por qué citamos a los alemanes y otros apuntes metodológicos", Política criminal (U. Talca), 2008, № 5, pp. 1-35, disponible en línea: http://politcrim.com/wp-content/uploads/2019/04/A_5_5.pdf (7 de mayo de 2019).

Mezzetti, Enrico, "Necessitas non habet legem?” Sui confini tra "impossibile ed "inesigibile" nella struttura dello stato di necessità, Giappichelli, Torino, 2000.

Novoa Monreal, Eduardo, "La integración jurídica latinoamericana", Revista de Derecho Universidad de Concepción, 1966, No 136, pp. 55-67.

Novoa Monreal, Eduardo, Alternativas y trances del derecho penal de hoy, Anuario de Derecho Penal y Ciencias Penales, 1978, Fascículo III, pp. 521-543.

Novoa Monreal, Eduardo, "Bases para una reforma en el área de las Ciencias Jurídicas (1969)", en: Centro de Estudios Políticos Latinoamericanos Simón 
Bolívar (eds.), Obras escogidas. Una crítica al Derecho tradicional, Ediciones del Centro de Estudios Políticos Latinoamericanos Simón Bolívar, Santiago, 1993.

Palazzo, Francesco; PAPA, Michele, Lezioni di diritto penale comparato, Giappichelli, Torino, 2013, $3^{\mathrm{a}}$ ed.

PAWLIK, Michael, Ciudadanía y derecho penal, Atelier, Barcelona, 2016.

Perin, Andrea, "Conocimientos científicos, tecnologías convergentes y Derecho penal”, en: Romeo, C. (ed.), Tecnologías convergentes: desafíos éticos y jurídicos, Comares, Granada, 2016, pp. 145-176.

PrADEL, Jean, "El derecho penal comparado. Breves reflexiones sobre una disciplina del futuro", en Nieto M, A (coord.), Libro de homenaje al Dr. Marino Barbero Santos: in memoriam, Ed. Universidad Castilla de la Mancha, Salamanca, 2001, pp. 479-487.

Pulitanò, Domenico, Diritto penale, Giappichelli, Torino, 2015, 6 a ed.

RADBRUCH, Gustav, Sul metodo comparativo, trad. it. Rocco Favale, Rassegna di diritto civile, 1997, $\mathrm{N}^{\mathrm{o}} 2$, pp. 477-480.

Rocco, Arturo, Opere giuridiche. Scritti giuridici vari, Vol. III, Società Editrice del Foro Italiano, Roma, 1933 ("Il problema e il metodo della scienza del diritto penale").

Rodríguez Devesa, José María, "El Derecho comparado como método de la política criminal", Anuario de ciencias penales, 1966, XIX, Fascículo I, pp. 5-13.

Rojas Aguirre, Luis Emilio, "El reducido espacio de la solidaridad en la Parte especial del Derecho penal chileno", Revista de Derecho (Valdivia), 2019, Vol. XXXII, No 1, pp. 295-310.

SAcCo, Rodolfo, Introduzione al diritto comparato, UTET, Torino, 1992.

Seminara, Sergio, "Divagazioni sulla nozione di accademia", Diritto Penale Contemporaneo, 2018, $\mathrm{n}^{\circ} 4$, versión .pdf, 9 p., disponible en línea: https://www. penalecontemporaneo.it/d/6223-divagazioni-sulla-nozione-di-accademia (visitada al 1 de julio de 2019).

Somma, Alessandro, Introducción al Derecho comparado, Trad. de Esteban Conde Naranjo, Ed. Universidad Carlos III de Madrid, Madrid, 2015.

Somma, Alessandro, "A chi servono i comparatisti? Diritto comparato, postdiritto e ruolo della comparazione", Comparazione e Diritto Civile, 2017, $\mathrm{n}^{\circ}$ 2, 7 p., disponible en línea: http:/www.comparazionedirittocivile.it/download/ volumi/201702.pdf (visitada al 13 de marzo de 2019).

Squella Narducci, Agustín, Filosofía del Derecho, Editorial Jurídica de Chile, Santiago, 2008.

VAN WeEzel, Alex, “¿Por qué no citamos más (por ejemplo, a los alemanes)? Réplica a J.P. Matus", Política criminal, 2008, No 6, pp. 1-5, disponible en línea: http://politcrim.com/wp-content/uploads/2019/04/Vol3N6D2.pdf (7 de mayo de 2019). 
VARONA Gómez, Derecho penal y solidaridad. Teoría y práctica del mandato penal de socorro, Dykinson, Madrid, 2005.

VIAL DEL Río, Víctor, Teoría general del acto jurídico, Editorial Jurídica de Chile, Santiago, 2006.

Viganò, Francesco, "L'influenza delle norme sovranazionali nel giudizio di 'antigiuridicità' del fatto típico", Rivista Italiana de Diritto e Procedura Penale., 2009, pp. 1062-1088.

Vinciguerra, Sergio, Le fonti culturali del diritto penale italiano, Cedam, Padova, 2008, pp. 8-15.

Vorbaum, Thomas, Historia moderna del Derecho penal alemán, Tirant lo Blanch, Valencia, 2018.

Wilenmann von Bernath, Javier, "El fundamento del estado de necesidad justificante en el derecho penal chileno", Revista de Derecho (Valdivia), 2014, Vol. XXVII, No 1, pp. 213-244.

Zitelmann, Ernst, "Compiti e importanza del diritto comparato" (1900), trad. de Rocco Favale, Rassegna di diritto civile, 1997, № 3, pp. 714-719.

\section{b) Jurisprudencia citada}

Corte Costituzionale (Italia), 25 de julio de 1994, Rol 341/1994, disponible en línea: http://www.giurcost.org/decisioni/1994/0341s-94.html (vista al $31 \mathrm{de}$ mayo de 2019).

Corte Costituzionale (Italia), 6 de marzo de 2019, Rol 141/2019, disponible en línea: http://www.giurcost.org/decisioni/2019/0141s-19.html) (vista al 31 de mayo de 2019). 